\title{
AGUSTÍN RIVERA, TEÓLOGO DEL LIBERALISMO: SERMONES Y DISCURSOS DE UN CLÉRIGO Y ESCRITOR PÚBLICO, 1854-1916
}

\author{
David Carbajal López \\ Universidad de Guadalajara-Centro Universitario \\ de los Lagos
}

UNA VOZ BULLICIOSA

¿ G s posible integrar los principios de la modernidad en la Eteología católica? A lo largo de la época contemporánea ha habido, sin duda, quienes se han planteado esta y otras preguntas semejantes, tendientes a conciliar la tradición medieval con el liberalismo. En este artículo analizamos la oratoria de un autor cuya obra parecía ir dirigida en buena medida por ese eje fundamental: Agustín Rivera. Vamos a comenzar relatando un incidente que nos muestra cuán de actualidad era entonces esta problemática.

El 27 de octubre de 1890 se conmemoraba en Lagos de Moreno, ciudad del noreste del estado de Jalisco, el aniversario de la muerte del comandante insurgente cuyo apellido ostenta esa urbe, Pedro Moreno. Con ese motivo, el Ayuntamiento y demás notables locales se dirigieron a la casa del historiador que había rescatado la memoria de dicho personaje con el fin de convertirlo en un héroe y ejemplo para las generaciones de entonces:

Fecha de recepción: 25 de junio de 2019

Fecha de aceptación: 16 de agosto de 2019 
doctor Agustín Rivera y Sanromán, clérigo y escritor público. Hombre ya sexagenario y enfermo, debió recibirlos en su recámara y de inmediato se efectuó un intercambio de discursos a propósito para la ocasión, primero de "uno de los miembros de la Junta Patriótica", y luego el del anfitrión, quien hizo girar su "arenga" a propósito "del progreso social desde el siglo x hasta el xix". ${ }^{1}$ En ese largo recorrido llamó la atención en particular la forma en que trató la revolución francesa, pues valoró positivamente su proclamación de los derechos del hombre.

Las palabras pronunciadas por Rivera desde su recámara en un rincón de los Altos de Jalisco generaron "un incendio en la prensa de varias ciudades”, según su propio decir. En su contra citó al periódico El Heraldo, mientras su defensa la emprendieron El Diario de Jalisco y otros tres periódicos de Guadalajara, uno de la Ciudad de México y, desde luego, los periódicos laguenses. No sin cierto aire de orgullo, concluía: "con motivo de mi arenga y de la fiesta de Moreno hubo una bulla tan grande como la Bulla Auctorem fidei". ${ }^{2}$ No vamos a reconstruir aquí ese debate en todos sus detalles, pero interesa subrayar algunos de sus aspectos. En primer lugar, su amplitud: las consecuencias de sus palabras fueron casi nacionales; en segundo lugar, su duración, pues aunque el autor firmó su respuesta a sus críticos el 6 de enero de 1891, la controversia se prolongó todavía al menos un mes más. En efecto, a falta de los periódicos que el propio autor mencionó, contamos con los testimonios de una publicación de la ciudad de Puebla, El Amigo de la Verdad. En el número del 24 de enero la redacción se congratulaba de la aparición en Guadalajara de una hoja suelta del "escritor católico"

${ }^{1}$ Seguimos aquí puntualmente el relato de Rivera, Tres artículos, pp. 5-6.

2 Rivera, Tres artículos, pp. 6-7. La bula en cuestión, emitida por el papa Pío VI, data de 1794, y condenaba diversas proposiciones del Sínodo de Pistoya, reunido por el obispo Scipione Ricci con el apoyo del Duque de Toscana Pedro Leopoldo de Habsburgo en 1786, y que fue uno de los grandes momentos del reformismo italiano del siglo xviII. 
Bruno Romero, y que describía "una tremenda felpa dada a ciertos escribidores liberalescos, falsificadores de historia". ${ }^{3} \mathrm{El}$ 14 de febrero el mismo periódico daba espacio en sus columnas al propio Romero con una colaboración titulada "El Dr. D. Agustín Rivera y sus defensores", nueva respuesta a Rivera. ${ }^{4}$

En sus Tres artículos nuestro autor había contestado a las críticas que se le habían hecho por rescatar los principios revolucionarios, distinguiendo entre sus principios y sus crímenes, ${ }^{5} \mathrm{y}$ sobre todo afirmando que esos principios habían sido aceptados ya por el catolicismo. Servían a su argumento tres referencias católicas: el "Sermón de la Vocación de Francia" del padre Lacordaire; el obispo Félix Dupanloup en De la pacificación religiosa, de quien citaba con énfasis: "aceptamos e invocamos los principios y las libertades proclamados en 1789"; y en fin, la aprobación que el papa León XIII había manifestado a propósito de la Constitución norteamericana y que se había difundido por la prensa. ${ }^{6}$ No era la primera vez que hacía esas afirmaciones, de forma que podía citar incluso la aprobación tácita del entonces arzobispo de Guadalajara, Pedro Loza y Pardavé. ${ }^{7}$ Ese consenso de autores católicos hacía a Romero elevar un lamento por una verdadera letanía de autores contrarrevolucionarios que habrían estado a favor de los principios de 1789 sin darse cuenta de ello: “¡Pobre Ségur! ¡Desdichado Barruel! ¡Infeliz Postel! ¡Triste Solá y Fonrodona! ¡Imbécil Chateaubriand! ¡Ciego Balmes! ¡Insensato Cebada! ¡Ignorante Berti...!”. ${ }^{8}$

3 “Los principios del 89", El Amigo de la Verdad (24 ene. 1891), p. 3. HNDM. ${ }^{4}$ Bruno Romero, "El Dr. D. Agustín Rivera y sus defensores", El Amigo de la Verdad (14 feb. 1891), pp. 2-3. HNDM.

${ }^{5}$ Rivera, Tres artículos, p. 1.

${ }^{6}$ Rivera, Tres artículos, pp. 1-6.

7 Rivera, Tres artículos, p. 7.

8 Bruno Romero, “El Dr. D. Agustín Rivera y sus defensores”, El Amigo de la Verdad (14 feb. 1891), p. 2. HNDM. 
La respuesta apuntaba a demostrar que el doctor Rivera profesaba principios condenados por la Iglesia. Además, había descalificaciones personales: burlas al aprecio por la inteligencia de Rivera y su insistencia de presentarlo como un hombre enfermo. Su mérito y su condición en realidad eran ideológicas, el primero era "el participio tan grande que tiene en las expansiones demagógicas en estas tierras", sobre la segunda exclamó: “¡Agonizante...! ¡Sí, agonizante en la ortodoxia!”. ${ }^{9}$ Otro de sus grandes pecados era su participación en el periódico El Defensor del Pueblo, que editaba Ausencio López Arce, "impío periódico que mancha lo que toca, que blasfema de lo que ignora". ${ }^{10}$ Con él la bulla llegó a ser más directa: El Amigo de la Verdad anunciaba en junio de 1892 que Romero había sido víctima de una "brutal agresión" de parte de López Arce. ${ }^{11}$ Fue una nueva oportunidad de los editores para ocuparse del "sacerdote renegado" Rivera, hasta revelar uno de los motivos fundamentales de su animadversión: "se persuade de que los católicos han de preferir su voz y sus enseñanzas a la voz de Roma y a las enseñanzas del Vicario de Jesucristo".

La voz del padre Rivera era, pues, tenida por peligrosa. Insistamos en el punto central de esa bulla de 1891: el orador había hablado del "progreso social", pero lo había relacionado con el catolicismo, hasta el punto de afirmar que éste aceptaba a aquél en su sentido radical y revolucionario. Su pecado fundamental es que había hecho católico el progreso, por así decir, desvirtuando, según sus críticos, al catolicismo. Desde luego, no podemos quedarnos sólo con esta visión de controversia. Para comprender lo que predicaba este orador es necesario explorar a detalle el

\footnotetext{
9 Bruno Romero, “El Dr. D. Agustín Rivera y sus defensores”, El Amigo de la Verdad (14 feb. 1891), p. 2. HNDM.

${ }^{10}$ Bruno Romero, "El Dr. D. Agustín Rivera y sus defensores”, El Amigo de la Verdad (14 feb. 1891), p. 3. HNDM.

11 “Agresión a un periodista católico", El Amigo de la Verdad (11 jun. 1892), p. 4. HNDM.
} 
testimonio que nos ha llegado de su "peligrosa” voz: las versiones impresas de diez sermones y 13 discursos que cubren casi dos terceras partes de la vida del autor, desde 1854 hasta 1916.

Por supuesto, debemos ante todo situarlo a él y a ese corpus documental en la historia mexicana y del catolicismo, y a sus sermones y discursos en el conjunto de su vida y trayectoria. Vamos a dedicar dos secciones para ello, correspondientes a las dos grandes etapas de la vida de Rivera. Enseguida, analizaremos ese corpus documental centrándonos en esa cuestión que se aprecia en el debate que hemos mencionado: ¿cómo hacía Rivera para integrar los principios del liberalismo, los de la revolución francesa, con la teología católica? En principio examinaremos si hay rasgos distintivos entre sermones y discursos, comenzando con sus temas explícitos y sus referencias, sirviéndonos además de un elemental ejercicio de lexicometría. En un apartado posterior veremos en cambio, apoyándonos en el vocabulario común de esos textos, la manera en que podían integrarse en un mismo planteamiento, podemos decir desde ahora, teológico.

Mas la riqueza de estos textos no se agota ahí, también es posible acercarnos por medio de ellos a otros aspectos del proyecto de sociedad que Rivera apoyaba, en temas como la sexualidad y las clasificaciones sociales, según veremos en la última parte. Todo ello nos ayudará a hacer un balance final sobre la significación, tanto para su época como para la nuestra, de este orador controvertido.

\section{LA FORMACIÓN DEL ORADOR Y SUS CONTEXTOS}

Agustín Rivera y Sanromán fue un hombre longevo. Nació en un rancho de la jurisdicción de Lagos en 1824 y murió en la ciudad de León en 1916. No es necesario aquí extendernos en los detalles, pero cabe decir que nació en el seno de una familia de élite local, de las que era común ver acumular capellanías que permitían a sus hijos acceder a las órdenes sagradas y a 
beneficios eclesiásticos, hasta el punto de formar verdaderas dinastías sacerdotales. No era un modelo raro en la entonces villa de Santa María de los Lagos, donde nació, ni lo era ver a las iglesias novohispanas e incluso del conjunto del mundo hispánico controladas por esas familias, según lo ha constatado la historiografía reciente. ${ }^{12}$

En ese sentido, no extraña que hiciera estudios en los seminarios de Morelia y Guadalajara, y que iniciara una carrera eclesiástica como profesor de este último. ${ }^{13}$ Sin embargo, incluso antes de salir de su natal Lagos había comenzado a formarse en la oratoria. En efecto, la biografía de Rivera nos recuerda hasta qué punto el discurso era elemento básico de la educación formal desde sus más elementales niveles y en general que la oratoria ha tenido una importancia fundamental en el mundo occidental, tradicional y moderno. En agosto de 1892, justo en uno de sus discursos, comenzaría recordando esa ya lejana ocasión de marzo de 1834 en que, siendo "un niño de diez años", con motivo de la entrega de premios a los alumnos de la escuela a que asistía, vestido de sacerdote pronunció de memoria un sermón del Viernes de Dolores. ${ }^{14}$ Escribiendo ya a principios del siglo xx, su biógrafo oficial no dejaba de estimar coherente que el público de notables que asistió al acto le pronosticara entonces "una brillante posición social". ${ }^{15} \mathrm{La}$ virtud de la palabra oral, forma básica de capital cultural, podía traducirse en capital social.

La escuela, sin embargo, no era el único vector que permitía a los fieles de entonces empaparse de una cultura oratoria. La

12 Sobre esas familias de la élite laguense véase Cruz, Vecinos de casa poblada. A propósito de las familias y la Iglesia de Guadalajara: САмACHO, "Beneficios eclesiásticos". En general es un tema abordado por ejemplo por Di Stefano, Elpúlpito y la plaza.

${ }_{13}$ MuÑoz, Rasgos biográficos, pp. 38-52.

${ }^{14}$ Rivera, Discurso pronunciado por Agustín Rivera en la función de distribución de premios, pp. 1-2. Destaquemos desde ahora la paradoja: Rivera recordaba un sermón al pronunciar un discurso.

15 MuÑoz, Rasgos biográficos, p. 11. 
historiografía nos ha mostrado bien la importancia del sermón en las festividades, ${ }^{16}$ pero además habría que destacar el papel desempeñado por los misioneros apostólicos franciscanos en la difusión de un modelo particular de oratoria, marcado por el patetismo y los efectos teatrales. ${ }^{17}$ Rivera lo conoció, y en su madurez lo criticó ampliamente: "cuando era yo niño de escuela”, recordaba en 1893, "una tanda de sermones" predicada por misioneros generaba incluso los desmayos de las mujeres. ${ }^{18}$

Frente a la oratoria barroca, los cursos en los seminarios de principios del siglo XIX mantenían la tradicional prioridad de las artes liberales relacionadas con el lenguaje (gramática, retórica, dialéctica), pero introducían algunos matices específicos. Fue sin duda ahí, en el seminario -en el de Morelia entre 1834 y 1836, y luego en el de Guadalajara-, donde tuvo una formación marcada por el clasicismo y el interés por la oratoria francesa. Es ya buen testimonio de ello el examen de Gramática que Rivera presentó en agosto de 1838, en que a sus 14 años habría traducido, a más de poesías, selectos discursos latinos. En concreto, se trató de un autor clásico: "las doce Oraciones Selectas de Cicerón", ${ }^{19}$ y de uno moderno y además local: la "Oración que el Dr. D. Juan

16 "Es un hecho, al parecer incontrovertible, que la mayor parte de los acontecimientos sociales, festivos o luctuosos, civiles o religiosos, se acompañaban de la prédica de un sermón", Chinchilla, "La república de las letras”, p. 82. "El sermón, en efecto, puede verse como artículo de primera necesidad e inevitable en la percepción festiva del tiempo en sus ritmos anuales" decía EgIDO, Los sermones.

17 Morán y Gallegos, "El predicador", ofrecen una síntesis de este tipo de oratoria. Acerca del sermón de misión existe la obra reciente de CHINCHILLA, El sermón de misión; sobre los colegios apostólicos en concreto sigue siendo importante remitir a BRADING, "La devoción católica".

18 Rivera, La pobre humanidad, p. 2.

19 Es posible que se trate de las Oraciones escogidas de Marco Tulio Cicerón, traducidas por Rodrigo de Oviedo, obra que tuvo varias ediciones en el mundo hispánico entre los siglos XVIII y xIx. Entre esos 12 discursos se cuenta la defensa de Aulo Licinio Arquias, citada por Rivera en dos de sus discursos, en particular en el último, que llegó a publicarse ya póstumamente. 
Nepomuceno Camacho dijo en el funeral del ilustrísimo señor Gordoa”. ${ }^{20}$ Más tarde, en agosto de 1841, en su acto de Moral y Religión, "además de las materias obligatorias, presentó al pie de la letra, de memoria e inteligencia", conferencias de dos eclesiásticos franceses: el canónigo Aymé y el conde de Frayssinous. ${ }^{21}$ En 1893 publicó fragmentos de un sermón del padre Charles Frey de Neuville, y decía haber tomado contacto con la obra de ese jesuita de tiempos de Luis XV desde mucho antes. ${ }^{22}$

Esta formación es testimonio del trabajo educativo del clero de la primera mitad del siglo xIx, entre cuyos proyectos conocemos en particular los del Seminario de Morelia con Mariano Rivas y Clemente de Jesús Munguía al frente. ${ }^{23}$ Sin rechazar el pasado, antes bien por el contrario manteniendo la prioridad de la gramática latina en conjunto con la española, introdujeron reformas renovando los autores que se estudiaban, introduciendo nuevos conocimientos (a veces incluso científicos), favoreciendo en el caso de la literatura el contacto con los clásicos y con los oradores modernos. Los autores que Rivera conoció entonces y que muchos años después siguieron marcando su labor de escritor público eran, en buena medida, los que entonces se promovían en las obras de esos educadore ${ }^{24} \mathrm{y}$ hasta se obsequiaban como premios en los actos públicos de fin de cursos: a más de los clásicos latinos de la Antigüedad, los predicadores del siglo XvII como Jacques Bénigne Bossuet, y los apologistas católicos del propio siglo XIX, como Chateaubriand y el padre Lammenais. ${ }^{25}$

\footnotetext{
20 MuÑoz, Rasgos biográficos, p. 20.

${ }^{21}$ MuÑoz, Rasgos biográficos, p. 26.

${ }^{22}$ Rivera, La pobre humanidad, p. 3.

${ }^{23}$ En particular gracias al estudio de Mijangos, The Lawyer of the Church, pp. 29-54.

${ }_{24}$ Para constatarlo baste ver la nómina de autores que utiliza Munguía, Estudios oratorios: Demóstenes, Cicerón, Fénelon, Massillon, Bossuet y Chateaubriand.

25 Además de la propia experiencia de Rivera que cita MuÑoz, Rasgos biográficos, p. 27, algunos ejemplos de listados de premios en Diario del Gobierno de
} 
No es de extrañar que, si algo valoró positivamente el resto de su vida, fue esa formación retórica recibida entonces. Cabe destacar que no se trataba de una oratoria fría, sino al contrario, y que además era ahí donde había aprendido a conciliar lo tradicional con lo moderno. Tenemos dos testimonios fundamentales al respecto en dos publicaciones relacionadas con temas de educación. En una dedicatoria de un folleto impreso a principios de la década de 1880 evocaba ampliamente a sus maestros en materias relacionadas con el Latín y el Derecho. Nos interesa la mención de dos de ellos, pues a uno le reconoció una capacidad emotiva tal, que su audiencia terminó con "pañuelos colocados sobre los ojos y sollozos universales", 26 y al otro lo describió como poseedor de una "elocuencia profundamente sentimental", comparable con "el bálsamo que destila el tronco del árbol que ha sufrido la incisión del hierro". ${ }^{27}$

Asimismo, diez años después, en una nota en otro folleto, el primero de los "tiernos recuerdos" que guardaba del Seminario de Morelia era el "Discurso sobre la urbanidad" que pronunciara Mariano Rivas, y cuya idea fundamental era relacionar la urbanidad y la fraternidad evangélica. ${ }^{28}$ También recordó la oratoria de Clemente de Jesús Munguía, de quien evocó principalmente su primer sermón, publicado bajo el título de "Panegírico de Jesucristo", y en el que observaba que el autor "había manejado más los libros de los publicistas y apologistas de la religión que las obras de los Santos Padres". ${ }^{29}$

No es raro que la primera pieza de oratoria que publicó Rivera fuera un sermón. Fue la quinta de sus publicaciones en general, y además fue un sermón propio de las tradicionales

\footnotetext{
la República Mexicana (28 dic. 1842), p. 47, y (20 sep. 1843), p. 78, así como en El Republicano (24 nov. 1846), HNDM.

${ }^{26}$ Rivera, Los Dos estudiosos, pp. ii-iv.

27 Rivera, Los Dos estudiosos, p. vi.

28 Rivera, La vocación, p. 41.

29 Rivera, La vocación, p. 44.
} 
celebraciones corporativas que habían ritmado el calendario de las ciudades episcopales del mundo hispánico, en este caso, la corporación de abogados. ${ }^{30} \mathrm{~A}$ más de orador, desde luego, nuestro protagonista siguió una trayectoria común entonces: ${ }^{31}$ de los estudios pasó a la docencia en el propio seminario tapatío, alcanzando pronto cargos (promotor fiscal) y grados (doctorado en 1852). Mas esa vida, tan conforme a los modelos que conocemos bien para épocas previas, comenzó a tener cambios en la década de 1850. El conflicto entre liberales y conservadores lo obligó a abandonar su carrera y, tras diversas peripecias, volvió a establecerse en su ciudad natal como escritor público, sin abandonar, empero, su carácter sacerdotal. ${ }^{32}$

Conviene decirlo desde ahora, ya para cerrar esta primera etapa, aun a riesgo de una interpretación tal vez muy directa de la relación entre sus discursos y su vida: en algún momento llegó a expresar, desde la tribuna, lo que acaso puede considerarse una crítica del contexto clerical en que había vivido en Guadalajara. Es posible que a ese ambiente se refiriera cuando, en el Discurso sobre los Hombres Ilustres de Lagos, evocaba "el hipódromo mundanal de los pingües beneficios y dignidades". ${ }^{33}$ Paradójicamente fue cuando ya estaba lejos de ese mundanal ruido clerical, que su voz comenzó realmente a escucharse.

\section{EL ORADOR Y ESCRITOR PÚBLICO}

La segunda época de la vida de Agustín Rivera es la que más nos interesa, aunque lamentablemente contamos con menos

\footnotetext{
30 Rivera, Sermón de la Natividad de María.

31 Muñoz, Rasgos biográficos, pp. 12-42, es la fuente principal para la vida de Rivera en todo este periodo. Aunque habría que hacer matices, esta carrera clerical no era muy distinta de lo que nos describen Aguirre, El mérito y la estrategia y TAYLOR, Ministros de lo sagrado, para el siglo XVIII.

32 MuÑoz, Rasgos biográficos, pp. 53-64.

33 Rivera, Discurso sobre los hombres ilustres, p. 14.
} 
estudios sobre la oratoria para establecer con claridad sus contextos. Son pocos aún los trabajos sobre la predicación de la segunda mitad del siglo xIx, ${ }^{34}$ y sobre todo, Rivera -como hemos visto- deja de ser testimonio para convertirse en una excepción respecto del movimiento bien conocido de la Iglesia hacia el ultramontanismo y el catolicismo social. ${ }^{35}$ Esto es, el ascenso de un catolicismo que rechazaba los principios modernos y revaloraba elementos de una identidad católica renovada, tanto en un sentido institucional (la centralidad de la figura del papa) como en las prácticas religiosas (devociones marianas, arte católico identificado con lo medieval, etcétera).

Fue con esta tendencia con la que nuestro autor debatió durante buena parte de esta época. La cuestión de la oratoria tuvo un papel en esas discusiones: desde finales de la década de 1880 se enfrascó en una querella contra los defensores de la cultura novohispana, en particular el canónigo Agustín de la Rosa. ${ }^{36}$ Aunque también le dedicó al tema otros textos menores, ${ }^{37}$ hay que recordar en particular el segundo tomo de sus Principios críticos (1888). ${ }^{38}$ Ese extenso tratado de poco menos de 400 páginas estuvo dedicado a la crítica sistemática de la oratoria barroca y a presentar como modelos, por un lado, a la oratoria de los apóstoles, y por otro, a la oratoria galicana de los siglos xvir y xviII.

${ }^{34}$ Hay señalamientos interesantes en BRISEÑo, "La moral en acción”, así como análisis de sermones concretos como los de Traslosheros, "Señora de la historia", sobre los que se predicaron en la coronación guadalupana de 1895, y desde luego, hay un estudio puntual del que Rivera pronunció en 1859 en Brading, Mexican Phoenix, pp. 252-255.

${ }^{35}$ La bibliografía es amplia, pero por tratar el caso particular de la Arquidiócesis de Guadalajara, que es obviamente el contexto en el que vivía Rivera y que no podemos detallar aquí, remitimos en particular a САмасно, Frente al hambre, pp. 39-107.

${ }^{36}$ Ha sido estudiada ya por Hernández, Dos ideas y Torre, "Polémica de Agustines".

37 Rivera, Juicio crítico; Rivera, El cempasúchil, pp. 16-23; Rivera, La pobre bumanidad.

38 Rivera, Principios críticos, t. 2. 
Casi sobra decirlo: además, defendía la utilidad de la oratoria sagrada para la educación y el progreso de la sociedad.

La publicación de sermones, como podemos ver en la tabla siguiente, fue mayormente posterior a esa obra y al debate que hemos visto en el apartado inicial. Después de sus dos primeros sermones, las siguientes piezas oratorias que publicó ilustran bien, no sólo estos cambios a nivel personal, sino también los que experimentaba el contexto cultural, político y religioso. En efecto, lo más evidente es el marco de los discursos: cuatro de ellos fueron pronunciados al final de cursos de escuelas y con motivo de entrega de diplomas y siete durante diversas fiestas cívicas, locales mayormente: cuatro fueron dichos en las fiestas anuales en honor a Pedro Moreno, y uno en una fiesta de carácter nacional. Nuestro autor fue parte del esfuerzo por construir el patriotismo que caracterizó al siglo xIx, y en particular su segunda mitad, cuando, ya durante la República restaurada y el porfiriato, el catolicismo dejó de cumplir esa labor de lazo político del pueblo mexicano para ser reemplazado por la "religión cívica" ${ }^{39}$ No es de extrañar que sus discursos hayan estado asociados con la construcción de monumentos y recintos públicos, así como con conmemoraciones de héroes y actos fundadores de la nación, que justo fueron algunos de los recursos más utilizados para afirmar los nuevos vínculos políticos del mundo occidental..$^{40}$ Uno de los momentos culminantes de esta trayectoria fue sin duda la participación de Rivera en el festejo del Centenario de la Independencia en 1910, que es testimonio también de la buena relación del autor con el régimen. ${ }^{41}$

\footnotetext{
39 Sobre esos esfuerzos, véase, entre otros, Lempérière, "Los dos centenarios"; PÉrez, "La modernidad".

${ }^{40}$ El artículo antes citado de Lempérière da cuenta ya de la importancia del ejemplo francés. Es la época de la "estatuomanía” que analizara ya AgulHon, Historia vagabunda, pp. 89-178.

${ }^{41}$ Rivera, Discurso pronunciado por Agustín Rivera en el Palacio Nacional.
} 
El marco de los sermones también se modificó. Cinco, es decir, la mitad de ellos, fueron pronunciados con motivo de celebraciones ya no tanto de orden corporativo sino familiar: las primeras comuniones de niños de familias laguenses cercanas al propio Rivera.

\section{Tabla 1}

SERMONES Y DISCURSOS IMPRESOS DE AGUSTÍN RIVERA, 1854-1916

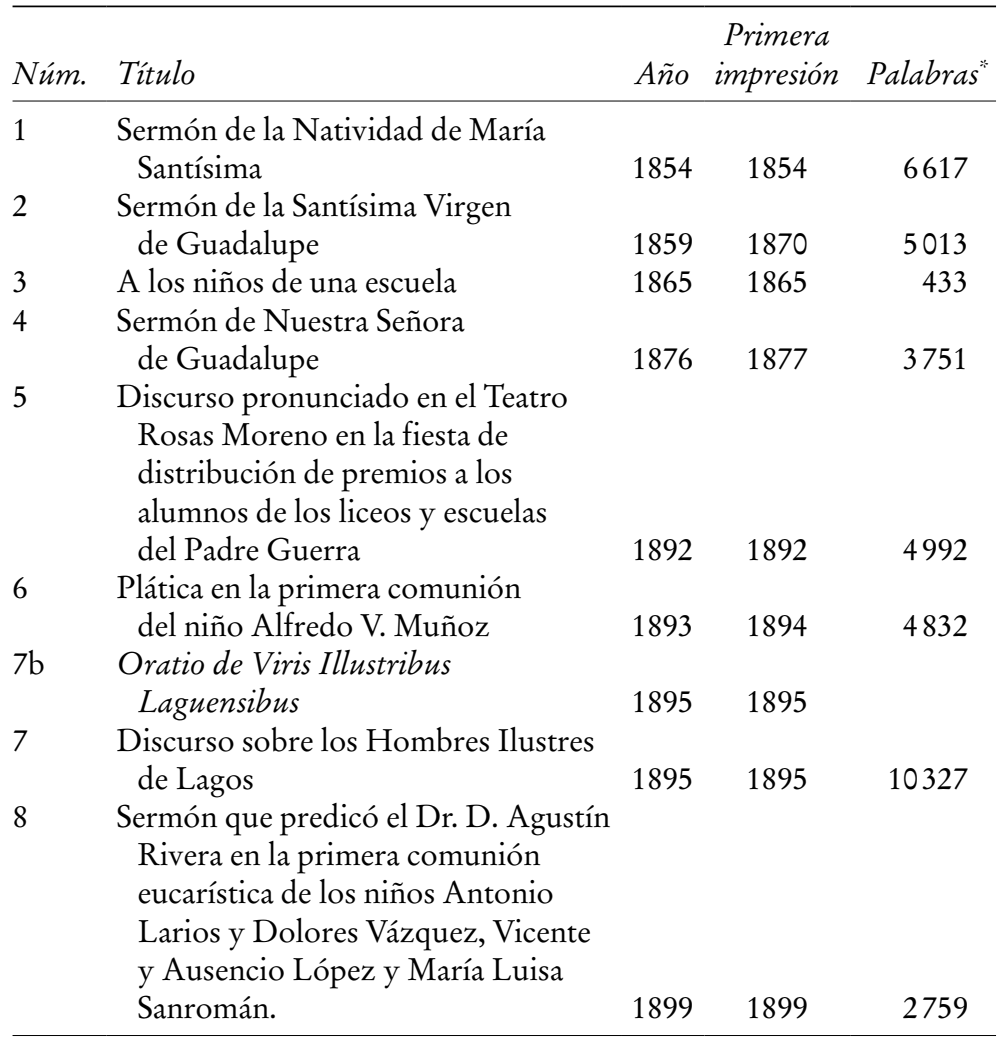

* Para el conteo de palabras hemos eliminado las notas a pie y al final, así como los cambios que el propio Rivera señala que introdujo en los textos al momento de publicarlos. Desde luego, no deja de ser sino una aproximación al número que efectivamente se pronunció de manera oral. 


\section{Tabla 1}

SERMONES Y DISCURSOS IMPRESOS DE AGUSTÍN RIVERA (COntinúa)

Primera

Núm. Título

Año impresión Palabras*

9 Despedida del siglo xIx. Discurso compuesto por Agustín Rivera y leído por el Lic. D. Ángel Castellanos en la ciudad de Comitán en una velada artístico-literaria... $\quad 1900 \quad 1901 \quad 3029$

10 Sermón de la Purificación de María $1901 \quad 1901 \quad 3036$

11 Sermón de la Santísima Trinidad $\quad 1901 \quad 1902 \quad 3568$

12 Arenga con que el señor Dr. D. Agustín Rivera contestó al recibir el Diploma. $1901 \quad 1901 \quad 890$

13 Arenga de Agustín Rivera el día de la fiesta en honra del héroe de la patria, Pedro Moreno, el 27 de octubre de 1902 $1902 \quad 1903 \quad 3845$

14 Discurso pronunciado por Agustín Rivera en la fiesta en honor del héroe de la patria Pedro Moreno, celebrada en Lagos de Moreno, el día 27 de octubre de 1903

15 Sermón de los Dolores y gozos del Sr. San José que predicó Agustín Rivera en la primera comunión eucarística que hizo la niña Genoveva Anaya y Anaya $1904 \quad 1904 \quad 3702$

16 Discurso que pronunció Agustín Rivera en la fiesta de la colocación de la primera piedra del Monumento a la memoria del héroe de la patria Pedro Moreno, en Lagos de Moreno, el día 15 de mayo de 1904

* Para el conteo de palabras hemos eliminado las notas a pie y al final, así como los cambios que el propio Rivera señala que introdujo en los textos al momento de publicarlos. Desde luego, no deja de ser sino una aproximación al número que efectivamente se pronunció de manera oral. 
Tabla 1

SERMONES Y DISCURSOS IMPRESOS DE AGUSTÍN RIVERA (concluye)

Primera

Núm. Título Año impresión Palabras"

17 Discurso que pronunció Agustín

Rivera en la Fiesta del 27 de octubre de 1906 en Lagos de Moreno $\quad 1906 \quad 1906 \quad 3100$

18 Sermón sobre la Eucaristía predicado por Agustín Rivera en la primera comunión del niño Agustín Muñoz $\begin{array}{llll}\text { Moreno } & 1907 & 1907 & 7282\end{array}$

19 Discurso sobre el teatro, pronunciado por Agustín Rivera en el Teatro Rosas Moreno en la fiesta de la conclusión del mismo teatro el 6 de agosto de 1907

20 Sermón sobre la Eucaristía predicado por el Sr. Dr. D. Agustín Rivera en la Primera Comunión de los niños Rafael y María Trinidad Chávarri

21 Discurso pronunciado por Agustín Rivera en el Palacio Nacional de la capital de México en la Apoteosis de los Héroes de la Independencia de México

22 La poesía estudiada a los 91 años 9 $1908 \quad 1909 \quad 3694$ meses o sea Discurso sobre la Poesía

* Para el conteo de palabras hemos eliminado las notas a pie y al final, así como los cambios que el propio Rivera señala que introdujo en los textos al momento de publicarlos. Desde luego, no deja de ser sino una aproximación al número que efectivamente se pronunció de manera oral.

Salvo por cuatro sermones y tres discursos, las otras 16 piezas fueron pronunciadas en Lagos. Los dos primeros sermones fueron dichos en Guadalajara y el tercero y el de la Purificación de 1901 lo fueron en San Juan de los Lagos. Como indican sus títulos, un discurso fue leído en Comitán, Chiapas, y otro, como ya hemos dicho, en la Ciudad de México, y el último en la ciudad 
de León, donde Rivera pasó sus últimos años. La pieza más pronunciada de Rivera parece haber sido el Discurso sobre el teatro, que en la nota final de la edición que tenemos afirma haberse pronunciado también en León y Aguascalientes..$^{42}$ Es decir, estamos ante piezas pensadas mayormente para un público local. En cuanto a su longitud, ya se advierte que la mayoría son breves: es significativo que entre los discursos, tres no llegan a las 2000 palabras y uno las rebasa por muy poco. Diez piezas están entre las 2700 y las 3900 palabras, entre ellas seis de los diez sermones; es decir, podrían pronunciarse en una media hora. Otras siete están dispersas en el amplio marco entre las 4800 y las 7400 palabras, pero gracias a su número es que el promedio general se eleva hasta 4133 palabras. Sin duda, el discurso más extenso fue "sobre los Hombres Ilustres de Lagos" (1895), que debió entretener a sus escuchas por más de una hora.

Debemos destacar asimismo que, salvo la Plática de 1894, los sermones que síllevan ese título fueron todos aprobados por la mitra de Guadalajara para su publicación. De hecho, los últimos cuatro pasaron a revisión de un mismo consultor, el Dr. Ramón López, canónigo y luego dignidad de la Catedral tapatía. Hasta donde los propios impresos informan, sólo el Sermón sobre la Eucaristía de 1907 tuvo alguna corrección importante, que obligó al autor a agregar 144 palabras que descontamos del conteo que aparece en la tabla 1 . El lector se extrañará posiblemente de esta ambigüedad. Hemos iniciado diciendo que la voz de Rivera generaba debates, y al recorrer su vida hemos identificado una primera etapa en que siguió una carrera clerical y una segunda en que más bien se dedicó a debatir con los autores católicos ultramontanos. Y sin embargo, sus sermones contaban con la aprobación de la mitra de Guadalajara para imprimirse. Volveremos sobre ello más adelante, pues vale la pena examinar si esto

42 Rivera, Discurso sobre el teatro, p. 29. 
puede considerarse un testimonio de que Rivera era capaz de distinguir entre lo que decía en el púlpito y desde una tribuna.

En fin, hay que considerar que, contrario a otros escritores de la época que hicieron además carrera política, aunque ejerció como capellán de monjas todavía hasta 1883 , nuestro autor tuvo la originalidad de vivir mayormente de su herencia y de su propio trabajo de escritor. Con ello trataba de hacer realidad la divisa que mandó colocar en la puerta de su casa: Usurae in calamo, "usuras en la pluma". ${ }^{43}$ En total publicó al menos 158 títulos, sin contar las ediciones posteriores, desde gruesos volúmenes a folletos breves, de los que 115 datan de 1884 en adelante, es decir, de la sexta década de su vida y hasta su muerte. Los sermones y discursos no fueron excepción, la mayoría (19) los publicó después de los 65 años, seis (tres sermones y tres discursos) alcanzaron una segunda edición, que es la que integramos aquí, y uno incluso una tercera: el Sermón de la Santísima Virgen de Guadalupe de 1859.

Por ahora, ya para finalizar este recorrido biográfico, hay que señalar que si el régimen conciliador de Díaz fue una buena época para Rivera, en cambio, la Revolución no le fue tan favorable, aunque trató de buscar apoyo en el bando carrancista. ${ }^{44}$ Orador, sin embargo, hasta casi sus últimos momentos, su trabajo final fue precisamente el Discurso sobre la poesía, que se publicó póstumamente incluyendo una carta fechada dos días antes de su muerte, y en la que remitía los originales del texto que había estado corrigiendo hasta entonces. ${ }^{45}$

43 En sus Recuerdos de mi capellanía, p. 3, afirmaba que entonces pensaba que “con mis pobres escritos, ganaría con usura más de lo que había ganado en empleos honoríficos en Guadalajara durante trece años”.

44 Rafael Muñoz Moreno, "Últimos días y muerte del preclaro escritor señor doctor Agustín Rivera”, El pueblo (6 ene. 1917), p. 3. HNDM citaba en concreto el apoyo de Manuel Aguirre Berlanga, Manuel M. Diéguez y Luis Castellanos Tapia.

45 Rivera, La poesía, p. 37. 
Ahora bien, vista ya su trayectoria y contexto, es necesario identificar qué es lo que transmitía Rivera en esos discursos patrióticos y sermones familiares.

\section{¿ORATORIA SAGRADA Y ORATORIA PROFANA?}

Las piezas de oratoria de Agustín Rivera respondieron, casi sobra decirlo, a las circunstancias específicas que motivaron su presentación. En general, pero sobre todo por lo que toca a los sermones, el autor era más bien clásico y preciso en su estructura, aunque sin duda no es extraño teniendo presente que se trata de piezas ya trabajadas, completadas con notas y editadas para su impresión. Nuestras diez piezas de oratoria sagrada se componen de un exordio y, normalmente, dos partes, comentando una cita bíblica en latín. Rivera tenía cuidado de dejar bien claro cuál era el "pensamiento" o "proposición” a desarrollar desde el inicio. La siguiente tabla los presenta, con excepción de una cita que sería demasiado extensa.

\section{Tabla 2}

LAS PROPOSICIONES DE LOS SERMONES DE AGUSTÍN RIVERA

\begin{tabular}{|c|c|c|}
\hline Núm. & Titulo & Proposición \\
\hline 1 & $\begin{array}{l}\text { Sermón de la } \\
\text { Natividad de María } \\
\text { Santísima }\end{array}$ & $\begin{array}{l}\text { "el nacimiento de María llenó de gozo el } \\
\text { universo: que desde la creación del mundo } \\
\text { hasta la edad presente, María ha sido la } \\
\text { esperanza y la alegría de los miserables hijos } \\
\text { de Adán”. }\end{array}$ \\
\hline 2 & $\begin{array}{l}\text { Sermón de la } \\
\text { Santísima Virgen } \\
\text { de Guadalupe }\end{array}$ & $\begin{array}{l}\text { "la aparición de Nuestra Señora de } \\
\text { Guadalupe es la visita de María al pueblo } \\
\text { mexicano para llamarlo al cristianismo, } \\
\text { santificarlo, civilizarlo y salvarlo". }\end{array}$ \\
\hline 3 & $\begin{array}{l}\text { Sermón de } \\
\text { Nuestra Señora de } \\
\text { Guadalupe }\end{array}$ & $\begin{array}{l}\text { "la Imagen de Nuestra Señora de Guadalupe } \\
\text { es una prueba de la alianza de María con el } \\
\text { pueblo mexicano, para la luz de todas las } \\
\text { gentes". }\end{array}$ \\
\hline
\end{tabular}


Tabla 2

LAS PROPOSICIONES DE LOS SERMONES (continúa)

\begin{tabular}{|c|c|c|}
\hline Núm. & Título & Proposición \\
\hline 4 & $\begin{array}{l}\text { Plática en la } \\
\text { primera comunión } \\
\text { del niño Alfredo V. } \\
\text { Muñoz }\end{array}$ & "los principales artículos de tu Credo". \\
\hline 5 & $\begin{array}{l}\text { Sermón que } \\
\text { predicó el Dr. D. } \\
\text { Agustín Rivera } \\
\text { en la primera } \\
\text { comunión } \\
\text { eucarística de los } \\
\text { niños Antonio } \\
\text { Larios y Dolores } \\
\text { Vázquez, Vicente y } \\
\text { Ausencio López } \\
\text { y María Luisa } \\
\text { Sanromán }\end{array}$ & $\begin{array}{l}\text { La relación de la entrada de Cristo en } \\
\text { Jerusalén con la eucaristía. }\end{array}$ \\
\hline 6 & $\begin{array}{l}\text { Sermón de la } \\
\text { Purificación de } \\
\text { María }\end{array}$ & $\begin{array}{l}\text { "La fe de María en su Purificación es el } \\
\text { modelo de la fe con que debéis orar." }\end{array}$ \\
\hline 7 & $\begin{array}{l}\text { Sermón de la } \\
\text { Santísima Trinidad }\end{array}$ & $\begin{array}{l}\text { "Todos los seres criados llevan el sello de la } \\
\text { Santísima Trinidad." }\end{array}$ \\
\hline 8 & $\begin{array}{l}\text { Sermón de los } \\
\text { Dolores y gozos } \\
\text { del Sr. San José que } \\
\text { predicó Agustín } \\
\text { Rivera en la } \\
\text { primera comunión } \\
\text { eucarística que } \\
\text { hizo la niña } \\
\text { Genoveva Anaya y } \\
\text { Anaya }\end{array}$ & $\begin{array}{l}\text { "Los dolores y gozos de Sr. San José, los } \\
\text { dolores y gozos de la humanidad, los dolores } \\
\text { y gozos de esta niña que viene a recibir por } \\
\text { primera vez la Eucaristía bajo el patrocinio } \\
\text { de Sr. San José.” }\end{array}$ \\
\hline 9 & $\begin{array}{l}\text { Sermón sobre } \\
\text { la Eucaristía } \\
\text { predicado por } \\
\text { Agustín Rivera } \\
\text { en la primera } \\
\text { comunión del niño } \\
\text { Agustín Muñoz } \\
\text { Moreno }\end{array}$ & $\begin{array}{l}\text { "La institución, efectos y riquezas de la } \\
\text { Eucaristía." }\end{array}$ \\
\hline
\end{tabular}




\section{Tabla 2}

LAS PROPOSICIONES DE LOS SERMONES (concluye)

\begin{tabular}{lll}
\hline Núm. & Título & Proposición \\
\hline 10 & Sermón sobre & "los desposorios [del alma con Cristo] los \\
& la Eucaristía & forma el amor y en la Eucaristía todo es \\
& predicado por & amor". \\
el Sr. Dr. D. & \\
Agustín Rivera & \\
en la Primera & \\
Comunión de & \\
los niños Rafael & \\
& y María Trinidad & \\
Chávarri & \\
\hline
\end{tabular}

El caso de los discursos tiene algunos matices. Hay cinco que repiten el modelo de los sermones y declaran explícitamente una proposición, pero el primer discurso fue en realidad unos versos breves, por lo que no hay una introducción, y dos de los discursos de las fiestas de Moreno tienen un contenido un tanto heterogéneo. De cuatro, en cambio, es posible identificar con mucha precisión un tema a desarrollar, aun si no está dicho explícitamente.

\section{Tabla 3}

PROPOSICIONES Y TEMAS DE LOS DISCURSOS CÍVICOS

DE AGUSTÍN RIVERA

\begin{tabular}{lll}
\hline Núm. & Título & Proposición \\
\hline 1 & A los niños de una escuela & Poesía \\
2 & Discurso pronunciado en el Teatro & "una palabra de \\
& $\begin{array}{l}\text { Rosas Moreno en la fiesta de } \\
\text { distribución de premios a los alumnos }\end{array}$ & felicitación y de consejo \\
& a las Niñas; una palabra \\
& & de felicitación y de \\
& esperanza a los jóvenes \\
& y a los niños”. \\
\hline
\end{tabular}


Tabla 3

PROPOSICIONES Y TEMAS DE LOS DISCURSOS (continúa)

\begin{tabular}{|c|c|c|}
\hline Núm. & Título & Proposición \\
\hline 3 & $\begin{array}{l}\text { Discurso sobre los Hombres Ilustres } \\
\text { de Lagos }\end{array}$ & $\begin{array}{l}\text { "vengo a proponeros } \\
\text { a vuestros ínclitos } \\
\text { conciudadanos como } \\
\text { ejemplares de las } \\
\text { virtudes cristianas y } \\
\text { cívicas". }\end{array}$ \\
\hline 4 & $\begin{array}{l}\text { Despedida del siglo xIx. Discurso } \\
\text { compuesto por Agustín Rivera y leído } \\
\text { por el Lic. D. Ángel Castellanos en } \\
\text { la ciudad de Comitán en una velada } \\
\text { artístico-literaria... }\end{array}$ & $\begin{array}{l}\text { La herencia del } \\
\text { siglo XIX. }\end{array}$ \\
\hline 5 & $\begin{array}{l}\text { Piezas Literarias en la fiesta de Moreno } \\
\text { en Lagos, } 30 \text { de octubre de } 1901\end{array}$ & La fiesta cívica. \\
\hline 6 & $\begin{array}{l}\text { Arenga de Agustín Rivera el día de la } \\
\text { fiesta en honra del héroe de la patria, } \\
\text { Pedro Moreno, el } 27 \text { de octubre de } 1902\end{array}$ & $\begin{array}{l}\text { "Voy a mostraros el } \\
\text { progreso universal, } \\
\text { poderoso y triunfante } \\
\text { en el siglo xx". }\end{array}$ \\
\hline 7 & $\begin{array}{l}\text { Discurso pronunciado por Agustín } \\
\text { Rivera en la fiesta en honor del héroe } \\
\text { de la patria Pedro Moreno, celebrada en } \\
\text { Lagos de Moreno, el día } 27 \text { de octubre } \\
\text { de } 1903\end{array}$ & $\begin{array}{l}\text { "Hoy quiero } \\
\text { proponeros a Pedro } \\
\text { Moreno como un } \\
\text { modelo de hombre de } \\
\text { trabajo". }\end{array}$ \\
\hline 8. & $\begin{array}{l}\text { Discurso que pronunció Agustín } \\
\text { Rivera en la fiesta de la colocación de } \\
\text { la primera piedra del Monumento a la } \\
\text { memoria del héroe de la patria Pedro } \\
\text { Moreno, en Lagos de Moreno, el día } 15 \\
\text { de mayo de } 1904\end{array}$ & Contenido heterogéneo. \\
\hline 9 & $\begin{array}{l}\text { Discurso que pronunció Agustín Rivera } \\
\text { en la Fiesta del } 27 \text { de octubre de } 1906 \text { en } \\
\text { Lagos de Moreno }\end{array}$ & Contenido heterogéneo \\
\hline 10 & $\begin{array}{l}\text { Discurso sobre el teatro, pronunciado } \\
\text { por Agustín Rivera en el Teatro Rosas } \\
\text { Moreno en la fiesta de la conclusión del } \\
\text { mismo teatro el } 6 \text { de agosto de } 1907\end{array}$ & $\begin{array}{l}\text { Definición, "utilidad” } \\
\text { e "influencia social” del } \\
\text { teatro. }\end{array}$ \\
\hline
\end{tabular}




\section{Tabla 3}

PROPOSICIONES Y TEMAS DE LOS DISCURSOS (concluye)

\begin{tabular}{lll}
\hline Núm. & Título & Proposición \\
\hline 11 & $\begin{array}{l}\text { Discurso pronunciado por Agustín } \\
\text { Rivera en el Palacio Nacional de la } \\
\text { capital de México en la Apoteosis de los }\end{array}$ & $\begin{array}{l}\text { “apoteosis de los } \\
\text { Padres de nuestra }\end{array}$ \\
$\begin{array}{l}\text { Héroes de la Independencia de México } \\
12\end{array}$ & $\begin{array}{l}\text { La poesía estudiada a los } 91 \text { años } 9 \\
\text { meses o sea Discurso sobre la Poesía }\end{array}$ & $\begin{array}{l}\text { Definición de poesía y } \\
\text { poeta, fines de la poesía. }\end{array}$ \\
\hline
\end{tabular}

Un sencillo ejercicio de lexicometría nos muestra, en principio, algo más de estas singularidades. Con un afán meramente descriptivo, hemos aplicado un análisis factorial de correspondencias al conjunto de nuestro corpus. Éste distribuye las piezas oratorias sobre dos ejes en función de las especificidades de las frecuencias de los términos utilizados en cada una, respecto de las frecuencias en el conjunto. De manera muy característica, el resultado ordenó automáticamente los sermones al lado izquierdo del eje vertical, y los discursos al lado derecho; es cierto que además el análisis muestra que los tres primeros sermones se distinguen de los posteriores en su vocabulario.

Para ilustrar mejor y de manera más precisa este punto, debemos señalar que en el conjunto de estas piezas hay tres sustantivos que se destacan por encima de todos las demás: Dios, María (con una frecuencia de 233) y Moreno. Vamos a dejar de lado por ahora la segunda, y a extender nuestro rastreo a otros términos asociados: todas las denominaciones de las personas de la Trinidad en el primer caso, y el otro gran héroe de la independencia que citaba con frecuencia Rivera, el padre Miguel Hidalgo. Podemos confirmar que la distribución absoluta de su presencia es contrastante, esto es que, como cabía esperar, era más común escucharle hablar de Dios en los sermones y no tanto en los discursos, y al contrario, el púlpito no lo utilizaba necesariamente para hablar de los héroes nacionales. La convergencia 
más equilibrada ocurre en realidad sólo en el "Discurso sobre los Hombres Ilustres de Lagos” de 1895.

Podría pensarse que, en ese sentido, uno era el padre Rivera predicando en el púlpito, y otro el doctor Rivera declamando en la tribuna. Acaso don Agustín era ya un hombre que podía distinguir perfectamente las sutilezas de la distinción entre las esferas de lo religioso y lo político, es decir, de la secularización, y lo mostraba al hablar ante uno y otro públicos.

En parte era efectivamente así. Otro aspecto cuantitativo interesante que nos lo muestra son sus citas. A pesar de sus propios consejos de oratoria en el sentido de recuperar a los predicadores galos del siglo xviI, en realidad en sus sermones Rivera predicaba citando ante todo la Biblia: hemos contado al menos 86 referencias, que proceden de los Evangelios (22), de las Epístolas de San Pablo (21) y de los Salmos (14) mayormente, y en menor medida de los Profetas (8), del Cantar de los Cantares (6), del Apocalipsis (4), del libro de los Proverbios (3), de las Epístolas de San Pedro (2), del Deuteronomio, Esdras, Hechos de los Apóstoles, Levítico, Macabeos y Sabiduría (1 en cada caso). En contraste sólo ocho discursos contienen un total de 28 referencias o alusiones bíblicas, 11 de las cuales aparecen en el Discurso sobre los Hombres Ilustres de Lagos de 1895, y 6 en el de 1892. Si los Evangelios son los más frecuentes (6), y le siguen siempre las Epístolas paulinas (3), las referencias se amplían a otros libros, como el Eclesiastés (3), Eclesiástico (3) y Job (2).

La Biblia en conjunto hubiera quedado en tercer lugar en las referencias de sus discursos cívicos, en los cuales es muy claro que Rivera recuperaba más bien la oratoria clásica. Los autores más mencionados y citados son todos de la Antigüedad romana: ${ }^{46}$ Virgilio al menos 37 ocasiones, Horacio 35 y

\footnotetext{
${ }^{46}$ En el conteo incorporamos tanto las menciones del nombre del autor como de sus obras, así como las citas que Rivera señaló como tales en las versiones impresas.
} 
Cicerón 20. A ellos les sigue uno de los pocos autores medievales que Rivera recuperaba: Dante Alighieri, concretamente la Divina Comedia, con 15 referencias. Si algo se nota en los discursos, en particular en el de 1895, es la correlación constante entre la gesta de Pedro Moreno y la Eneida de Virgilio. ${ }^{47}$ San Agustín y Santo Tomás de Aquino, que tenían una presencia muy significativa en los sermones, se quedan muy atrás, con $9 \mathrm{y}$ 3 referencias únicamente; la obra de Cornelio Alápide, asimismo muy citada en los sermones, está completamente ausente.

Sin duda, en uno y otro corpus documental el autor que más se echa en falta es el padre Benito Gerónimo Feijoo. ${ }^{48}$ Rivera, el "Feijoo mexicano", lo citó en sus piezas de oratoria apenas dos veces. Más todavía, recibió ese sobrenombre por su crítica de las prácticas religiosas, que sin embargo no aparece en sus sermones, salvo por dos leves alusiones: una indirecta, en la Plática de 1894 al mencionar desde el púlpito "preocupaciones, consejas y patrañas", y otra ya más en tono de reproche en el que predicó en San Juan de los Lagos en 1901, en que se limitaba a recomendar la meditación en lugar de los rezos apresurados. ${ }^{49}$ La cátedra del Espíritu Santo parecía no ser, para Rivera, el lugar adecuado para la crítica. Lo era en cambio el espacio profano de la oratoria cívica, o al menos eso pareciera indicar la presencia relativamente constante, de un vocabulario asociado a lo negativo del pasado y de la tradición: el "antaño", las "añejas preocupaciones" (prejuicios diríamos hoy), lo "colonial”, las “consejas”, las "supersticiones", que se asociaban con ciertos personajes: los "analfabetas" (adjetivo de campesinos, pueblo y plebe), femeninos sobre todo (las "viejas", las "beatas"). Sólo el primer poema y el Discurso sobre la poesía dejan por completo de lado ese

\footnotetext{
47 Rivera, Discurso sobre los Hombres Ilustres, pp. 5-9 en particular.

48 Connaughton, "Agustín Rivera".

49 Rivera, Plática de Agustín Rivera, p. 2 y Rivera, Sermón de la Purificación, p. 5.
} 
vocabulario. Casi sobra decirlo, todo ello estaba asociado con ciertas creencias y prácticas religiosas, que resumía así en 1906:

[...] los milagros de San Expedito, las Profecías de Matiana, frecuentes apariciones de muertos, toques frecuentísimos de San Pascual Bailón; el culto a un San Gonzalo Bailón [...], el Santiago a caballo matando indios [...] el San Lázaro de Puebla, a quien como consta por la Historia de la ciudad, ofrecen los niños los primeros dientes; la creencia supersticiosa de que [de] dos o más Imágenes de la Madre de Dios, una es más poderosa que otra; la Burra de María Santísima $[\ldots]^{50}$

Autor crítico de la oratoria sagrada, habló de ella e hizo elogio de grandes oradores, pero no en los sermones, sino en los discursos cívicos. Fue en ellos que retomó sus cuestionamientos de la oratoria barroca: en su discurso de 1892 aprovechaba para burlarse de una "gerundiada" de un sermón en honor de los santos Crispín y Crispiniano del padre Juan de Villa y Sánchez; en la arenga de 1902, incluía entre los elementos culturales felizmente olvidados a "los sermones del Padre Vieyra".$^{51}$ En contraste, el Discurso sobre los Hombres Ilustres de Lagos destaca por su elogio de la buena oratoria de tres eclesiásticos, ${ }^{52}$ de quienes incluyó extensas citas de dos sermones: 929 palabras del que con motivo de la consumación de la independencia pronunció fray Francisco Garciadiego, luego obispo de California, en el Colegio Apostólico de Guadalupe de Zacatecas en 1821, y 394 de la Oración fúnebre que en las honras del obispo José Miguel Gordoa pronunció el canónigo Pedro Barajas, quien luego lo

50 Rivera, Discurso que pronunció Agustín Rivera en la fiesta, p. 7.

51 Rivera, Discurso pronunciado por Agustín Rivera en la función de distribución de premios, p. 12. Rivera, Arenga de Agustín Rivera el día de la Fiesta, p. 6.

52 Rivera, Discurso sobre los Hombres Ilustres de Lagos, pp. 3, 12, 29. 
fue de San Luis Potosí. ${ }^{53}$ Del primero le interesaba la crítica del régimen colonial y del segundo la presentación de un prelado que habría reunido catolicismo y liberalismo.

Fue en sus discursos del Centenario de la Independencia y sobre la Poesía donde llegó a mencionar esporádicamente a Bossuet, y en este último además a Jean-Baptiste Massillon, sus grandes ejemplos de oratoria sagrada..$^{54}$ Sólo en 1904, habría de dedicar un párrafo al elogio de la "oratoria tribunicia", es decir, la que se usaba en las fiestas cívicas, "que enseña, ilustra y educa al pueblo, que no se conoció en las monarquías absolutas", y que caracterizaba como un discurso público, libre, democrático y razonado. Mas de inmediato introdujo argumentos de autoridad aprovechando los sermones de los obispos José de Jesús Ortiz y Atenógenes Silva en respaldo de la catolicidad de su visión de la historia patria, condenando el pasado colonial y reivindicando el prehispánico. ${ }^{55}$

En sentido inverso, en los sermones no hemos podido identificar citas de discursos cívicos, y sólo las hay muy puntuales en los propios discursos. La arenga de 1902 mencionaba dos concretamente: la oración fúnebre que con motivo de las honras fúnebres del general Mariano Matamoros pronunció el licenciado Rafael Zayas Enríquez, y otra obra del mismo género que no cita con precisión pronunciada por el licenciado José María Sierra. ${ }^{56}$ Esto es, Rivera aprovechaba la oratoria, pero sobre todo la oratoria sagrada para probar en la oratoria cívica la legitimidad asimismo religiosa de sus afirmaciones. Es también característico de ello sus referencias a los dos grandes papas del siglo xix: Pío IX y, sobre todo, León XIII. El primero sólo

\footnotetext{
${ }^{53}$ Rivera, Discurso sobre los Hombres Ilustres de Lagos, pp. 17-19 y 26-31.

${ }^{54}$ Rivera, Discurso pronunciado por Agustín Rivera en el Palacio Nacional, p. 5 y Rivera, La poesía estudiada a los 91 años, p. 22.

55 Rivera, Discurso que pronunció Agustín Rivera en la fiesta de la colocación de la primera piedra, pp. 4-5.

${ }^{56}$ Rivera, “Arenga con que el Sr. Dr. D. Agustín Rivera contestó”, p. 9.
} 
está mencionado tres veces en su primer sermón, una vez en su discurso de 1892 y otra en la arenga de $1902 .{ }^{57}$ El segundo no aparece ni una sola vez en sermones, pero en cambio sí lo hace en cinco discursos distintos, bien que, como señalamos al principio, aludía sobre todo a un texto: la epístola a los ciudadanos de Estados Unidos de 22 de enero de 1899, donde "para confundir a los partidarios del antaño”, habría hecho un elogio del progreso material y de la constitución de esa nación. ${ }^{58}$

Con esto franqueamos ya la posibilidad de la separación absoluta entre discursos cívicos profanos y sermones estrictamente religiosos. En realidad, aunque nuestro autor hiciera distinciones entre la oratoria sagrada y la tribunicia, esa frontera era atravesada en un sentido muy concreto: no había crítica religiosa en los sermones, pero sí había, y esto es lo que más interesa destacar, mensajes religiosos en los discursos, como había ocurrido también en 1891. Sobre ese eje se constituía un vocabulario común en ambos tipos de oratoria, según veremos enseguida.

\section{ANTROPOLOGÍA CATÓLICA Y TEOLOGÍA DEL LIBERALISMO}

En 1893, ya lo hemos mencionado, Agustín Rivera publicó un folleto en que se reproducían fragmentos de un sermón del padre Charles Frey de Neuville. Entonces aprovechó para exponer de manera más precisa lo que esperaba de la oratoria: a través del "retrato de caracteres", debía ayudar a evidenciar las debilidades del "genio" natural de los hombres, y desde luego,

${ }^{57}$ Rivera, Sermón de la Natividad de María, pp. 12-13. Rivera, Discurso pronunciado por Agustín Rivera en la función de distribución, p. 10. RIVERA, Arenga de Agustín Rivera el día de la Fiesta, p. 5.

${ }^{58}$ RIVERA, Discurso pronunciado por Agustín Rivera en la función de distribución, p. 10. La cita procede de RIVERA, Despedida del siglo XIX, p. 7. Rivera, Arenga de Agustín Rivera el día de la Fiesta, p. 5. Rivera, Discurso pronunciado por Agustín Rivera en la fiesta en honor, p. 1. RIVERA, Discurso sobre el teatro, p. 7. 
abrir el camino para "reprimir[lo] y rectificar[lo]"59 a través de la emoción. Tal había sido el motivo por el que había considerado superior a Massillon frente a Cicerón: era capaz de una emotividad mucho mayor. ${ }^{60}$ En sus sermones es cierto que llegó a realizar ejercicios de este tipo, sobre todo en los que predicó de 1899 en adelante. El que pronunció en ese año, por ejemplo, al disertar sobre el llanto de Cristo en el pasaje de su entrada triunfal en Jerusalén, lo tomaba directamente como modelo para que la niñez no olvidara el arrepentimiento de los pecados incluso en los momentos de felicidad. El de 1901, presentaba a la Virgen María como modelo de fe y de oración, y en 1904 hacía lo propio con San José, repitiendo el tema del dolor en la alegría. ${ }^{61}$

Ya en sus discursos anteriores había apuntes en este sentido. En sus versos de 1865 contrastaba dos modelos, el "animal bravo" y la "criatura racional". En el discurso de 1892, recomendaba a las jóvenes del liceo de Lagos libros donde encontraran modelos y contramodelos; de hecho, la Biblia misma debía servirles para identificar "multitud de mujeres ilustres y santas a quienes podéis imitar", y por el contrario retratos de la avaricia y de la hipocresía en los personajes de las parábolas de los Evangelios. ${ }^{62}$ El Discurso de los Hombres Ilustres de Lagos era finalmente una colección de retratos de hombres "ejemplares de las virtudes cristianas y cívicas"; no por nada el orador repite ocho veces con énfasis la fórmula "Imitad a" ${ }^{63}$ Más todavía, uno de los motivos por los que aplaudió ahí a don Pedro Barajas fue la exitosa presentación de un "retrato de caracteres", en este caso

59 Rivera, La pobre bumanidad, pp. 4-5.

60 Rivera, El cempasúchil, p. 17.

61 Rivera, Sermón que predicó el Dr. D. Agustín Rivera en la Primera Comunión. Rivera, Sermón de la Purificación de María. Rivera, Sermón de los dolores i gozos de Sr. San José.

62 Rivera, Discurso pronunciado por Agustín Rivera en la función de distribución, p. 9.

63 Rivera, Discurso sobre los Hombres Ilustres de Lagos, pp. 5, 6, 7, 10, 20, 26 y 31 . 
el retrato del ambicioso que citó completo, en contraste con la humildad del obispo Gordoa. ${ }^{64}$ Por el mismo camino va el elogio a José Rosas Moreno: su fábula de "La estatua, el escultor y la piedra" la calificó de "digna de ser grabada con letras de oro en el aula mayor de nuestros Liceos" porque la consideraba una metáfora -muy directa cabría decir- de cómo debía ser la educación de los jóvenes, imitando una representación de Cristo a fuerza de dolor, ${ }^{65}$ imagen que casi extraña no encontrar en alguno de sus sermones.

Como cabía esperar entonces, los discursos sobre el teatro y sobre la poesía enfatizan su utilidad asimismo educativa y moral. Si la poesía se distinguía porque "excita vehementísimamente los sentimientos", ${ }^{66}$ el teatro tenía sobre los otros géneros literarios la ventaja de la emotividad superior del realismo. En él, afirmaba, "se ve a los hombres con su propia fisionomía, con su propio vestido, con sus modales, se escucha con los oídos del cuerpo su propio lenguaje, y éste, el acento de su voz, su gesto, su mirada [...] dan a conocer sus virtudes y sus vicios" ${ }^{67} \mathrm{La}$ comedia en particular, con sus numerosos "tipos sociales" ridiculizados, parecía casi asemejarse al "retrato de caracteres" que había elogiado en los oradores del siglo xviI..$^{68} \mathrm{En}$ fin, con todos estos recursos el teatro era capaz, ni más ni menos, de infundir en el pueblo "las ideas de lo noble, de lo justo, de lo bello, la inclinación a los placeres del intelecto, de la imaginación y el sentimiento, y el desafecto a lo bárbaro". ${ }^{99}$ Un género literario que

\footnotetext{
${ }^{64}$ Rivera, Discurso sobre los Hombres Ilustres de Lagos, p. 29 y ss.

${ }_{65}$ Rivera, Discurso sobre los Hombres Ilustres de Lagos, p. 33.

${ }^{66}$ Rivera, La poesía estudiada a los 91 años, p. 14.

${ }^{67}$ Rivera, Discurso sobre el teatro, p. 4.

${ }^{68}$ Rivera, Discurso sobre el teatro, p. 9 y Rivera, La pobre humanidad, pp. 4-5.

69 Rivera, Discurso sobre el teatro, p. 11. Cabe destacar que para nuestro autor, además, el teatro había tenido incluso un papel político en las revoluciones liberales. Citaba al respecto dos casos concretos: primero, el 5 de agosto de 1830 la representación en Bruselas de la ópera La Muette de Portici de Daniel
} 
no cumpliera con esa función moral no era realmente tal, según sentenciaba en el Discurso sobre la Poesía: "Toda composición literaria inmoral, aunque lleve el título de poesía, no lo es”. ${ }^{70}$

Lo mismo aplicaba para la música. Nuestro autor sólo mencionó a 15 músicos en sus sermones y discursos, mayormente del siglo XIX, únicamente Gregorio Allegri y Wolfgang A. Mozart datan de otra época, y mencionó sólo obras de contenido religioso (Stabat Mater de Rossini, Credo de Mercadante) o de importancia directamente política, como La Marsellesa, o que podían interpretarse en ese sentido: "aun el canto de los mártires en las Catacumbas en el Poliuto de Donizetti, es un canto de libertad, de la libertad de la conciencia”, llegó a decir. ${ }^{71}$

De manera muy explícita pues, la oratoria sagrada y cívica de Rivera transmitía un mensaje de promoción de la moral y la virtud para corregir una naturaleza humana que, de conformidad con la antropología católica, no podía sino estar marcada por la debilidad del pecado. ${ }^{72}$ Mas debemos agregar un matiz aquí: el

Auber habría despertado "las energías latentes del pueblo belga, esa misma noche dio el Grito de Independencia y hasta hoy es independiente de Holanda" (pp. 5-6); segundo, la representación de la comedia Las bodas de Fígaro de Beaumarchais, habría sido más efectiva que "las tragedias de Corneille, de Racine y de Voltaire", y que las obras de Montesquieu y Rousseau, ninguna de las cuales "habían podido derribar la Bastilla". La comedia, al ridiculizar "muchos tipos de la aristocracia", "conmovió universalmente al pueblo" y habría contado como una causa de la revolución francesa de 1789: "Despertaron los galos del tiempo de César, despertó el pueblo de Vercingetorix y comenzó a ejercitar sus derechos" (pp. 7-8).

70 Rivera, La poesía estudiada a los 91 años, pp. 11-16. El autor volvía sobre un tema que había esbozado desde tiempo atrás en otros textos. En otro momento, se ha señalado (CARBAJAL, "Entre concordancias", pp. 318-319), Rivera criticaba desde principios de la década de 1880 a la literatura romántica (Víctor Hugo, Eugène Sue, entre otros) por razones morales.

${ }^{71}$ Rivera, Discurso sobre el teatro, p. 13.

72 Rivera, Concordancia de la razón y la fe, fue el desarrollo más amplio de Rivera, al menos hasta donde sabemos, respecto de las consecuencias del pecado sobre la naturaleza humana. 
"genio" o el "carácter" no era sólo individual para Rivera, sino también colectivo; podía haber, lo decía casi al final de su último discurso, "carácter nacional, que distingue a cada nación de las demás". Se refería al de España, a fin de explicar el éxito del Tenorio de Zorrilla, pero conviene enfatizarlo, se trata también de un hecho antropológico que aparece en sus discursos. Lo podemos constatar a través de nuestra aproximación lexicométrica. Términos como "nación", "pueblo" y "patria" se encuentran presentes, de manera "natural", podríamos decir, tanto en los sermones como en los discursos.

Si algo pareciera haber estado fuera del horizonte de posibilidades de nuestro autor es pensar otras formas de agrupación humana fuera de esos tres términos, que además eran prácticamente equivalentes entre sí, y parecían ser "naturales”, o más aún, se diría que eran conformes con una voluntad divina. "Cada criatura, cada nación, tiene un destino y una vocación particular", advertía ya en el segundo de sus sermones, que junto con el primero son de los que más destacan como relatos de una historia providencialista universal, marcada por la figura de la Virgen María. Más adelante lo señalaba: era "la voluntad inescrutable del Altísimo" la que establecía el momento de asumir esa "vocación particular". ${ }^{73}$ Esas unidades de la historia sagrada y profana tenían pues una dirección que seguir, la del progreso. Esto es algo que otros estudios ya han señalado, ${ }^{74}$ nuestro autor era optimista con la naturaleza humana. Esto se confirma con la

\footnotetext{
73 Rivera, Sermón de la Santísima Virgen de Guadalupe, pp. 4 y 6 para las citas concretas. El Sermón de la Natividad de María había estado dedicado a defender la idea de que todos los pueblos del mundo habían conocido la creencia en la Virgen María, aun sin estar conscientes de ello. En esta segunda pieza, interpretaba de manera particular la legendaria aparición de la Virgen de Guadalupe del Tepeyac como momento definitorio de la historia de la nación.

${ }^{74}$ Sobre el uso por Rivera de términos como liberalismo, fanatismo, antaño, progreso, etc.: Connaughton, "Agustín Rivera"; Cortés, "Liberalismo y civilización”, y Connaughton, “Agustín Rivera; ¿autor liberal de planteamientos modernos?"
} 
importancia, diferenciada es cierto, que tenían en sus sermones y discursos los conceptos de "progreso", asociado a "civilización”, y su opuesto, el “antaño”.

Presencia discontinua, evidentemente, que encabezan los discursos, pero que no excluye del todo a los sermones, sobre todo, de nuevo, al segundo. Rivera enseñaba, tanto desde el púlpito como desde la tribuna, pero de manera más insistente en los escenarios laicos, que los seres humanos, colectivamente y de manera natural, progresan. "El progreso es una ley natural, perpetua e indefectible”, sentenció en su discurso de 1892 en el Teatro Rosas Moreno. ${ }^{75}$ Colectivo, fatal y múltiple, era además un proceso universal contemporáneo, pues triunfaba en particular en esa segunda mitad del siglo XIX, incluso en México, desde luego gracias al "gran Gobernante”, Porfirio Díaz, quien "ha hecho progresar en todas las líneas" a la república, según decía en el Discurso del Centenario. Sin embargo, ese progreso era además necesariamente obra de una minoría. Era esto lo que daba sentido a los elogios de individuos muy concretos como los del Discurso sobre los Hombres Ilustres de Lagos (1895). Entonces invocaba a la Historia como testigo de este principio elitista: "poquísimos han acometido y comenzado las grandes empresas, y sin embargo, han vencido a muchos, y al fin a todos". ${ }^{76} \mathrm{El}$ vínculo entre esa minoría y el resto de la sociedad era la educación. De ahí que entre los "hombres ilustres" que seleccionaba Rivera tuvieran un lugar destacado los fundadores de escuelas, como el padre Miguel Leandro Guerra, pero también los literatos, como José Rosas Moreno. ${ }^{77}$

Civilizar y progresar son dos verbos estrechamente relacionados en este autor, pero cuando se trataba de civilización tenía el adjetivo particular de cristiana. En efecto, ya en el primero de

\footnotetext{
75 Rivera, Discurso pronunciado por Agustín Rivera en la función de distribución, p. 10.

76 Rivera, Discurso sobre los Hombres Ilustres de Lagos, p. 5.

77 Rivera, Discurso sobre los Hombres Ilustres de Lagos, pp. 22-25 y 32.
} 
sus sermones hablaba de la "civilizadora creencia de María", ${ }^{78}$ mientras el segundo estuvo explícita y específicamente dedicado a mostrar "el establecimiento y propagación del cristianismo en México y su consiguiente civilización”, ${ }^{79}$ gracias a la Virgen de Guadalupe. Aunque no volvió a explicarse más ampliamente al respecto, en esos dos sermones se diría que el cristianismo es la raíz misma de la civilización. Todos los aspectos que se asocian en estas piezas oratorias al progreso terminaban teniendo esa raíz celestial: hoy no nos suena extraño oírlo respecto de los “templos magníficos, monasterios”, pero lo decía igualmente de los "colegios de educación científica, academias de bellas artes, teatros", y también de los "hospicios, hospitales”, e incluso "fábricas de la industria”, que eran "huellas todas de un pueblo civilizado” y que no existían en el México del siglo XIX sino “por Nuestra Señora de Guadalupe” ${ }^{80}$ En la Plática de 1894 lo reitera de manera muy directa, "los católicos y los protestantes" eran “el mundo civilizado”, y más aún, "la religión de Dios venció a la antigua Grecia y a la antigua Roma, ha civilizado al mundo". ${ }^{81}$

Es verdad que no es algo tan presente, en cambio, en los discursos cívicos. Empero, aparece bien en la Despedida del siglo XIX. A la distancia, decía a los miembros de la Sociedad Agustín Rivera de Comitán: "veo brillar en vuestro pecho la cruz redentora y civilizadora de Jesús de Nazareth”. ${ }^{82}$ El cristianismo no se contraponía, sino antes bien resultaba el origen mismo de los principios del progreso y hasta de la modernidad política. Teólogo del liberalismo, la arenga de 1902 lo explicaba bien: la higiene y la medicina eran "hija[s] del progreso moderno”, y habían permitido la longevidad del papa León XIII, la cual si bien “es efecto de la Providencia de Dios”, había que

\footnotetext{
78 Rivera, Sermón de la Natividad de Maria, p. 7.

79 Rivera, Sermón de la Santísima Virgen de Guadalupe, p. 4.

80 Rivera, Sermón de la Santísima Virgen de Guadalupe, pp. 7-8.

81 Rivera, Plática de Agustín Rivera en la primera comunión, p. 9.

82 Rivera, Despedida del siglo XIX, p. 2.
} 
destacarlo, "no es menos cierto según la teología católica que la Providencia de Dios obra por medio de las causas segundas". ${ }^{83}$ Visto esto, no sorprende que en el Sermón sobre la Eucaristía de 1907 -que hemos citado en otro momento-alegara que los derechos del hombre, la libertad y la igualdad, eran producto del Evangelio. De hecho, la libertad, "el primero de los derechos del hombre", había sido "establecido por las leyes de la naturaleza y confirmado y perfeccionado por el Evangelio". ${ }^{84} \mathrm{Al}$ año siguiente, en el Sermón de la Trinidad insistiría: “el Cristianismo [es] la Religión de la Libertad". 85

En suma, en última instancia, sermones y discursos coincidían en una teleología, que era además producto de una teología. La oratoria de Rivera afirmaba con mayor o menor sutileza que Dios estaba detrás del progreso del hombre, y que era Él quien había querido los principios fundamentales del liberalismo. Ahora bien, es importante entrar todavía en el detalle de esos sueños de progreso del orador.

\section{DESIGUALDADES DE ANTAÑO Y DEL PROGRESO}

Los sermones y discursos de Rivera, como hemos visto, planteaban explícitamente una proposición principal. Sin embargo, hay también varios temas que trataban además del principal y que nos ilustran sobre la sociedad que el orador esperaba para ese futuro de progreso. Vamos a centrarnos en torno a una paradoja que nos parece muy evidente, acerca de la igualdad. Era un tema explícitamente importante para el autor: cuatro piezas oratorias, dos sermones y dos discursos lo mencionan con precisión. Más todavía, era un tema fundamental para su intento de conciliar catolicismo y liberalismo. En su sermón de 1899 caracterizaba

\footnotetext{
83 Rivera, Arenga de Agustín Rivera el día de la Fiesta, p. 6.

${ }^{84}$ Rivera, Sermón sobre la Eucaristía, p. 13.

${ }^{85}$ Rivera, Sermón de la Eucaristía, p. 6.
} 
al cristianismo como "la Ley de Gracia, de amor, de libertad, de igualdad". ${ }^{86}$ Reprochaba, desde luego, la desigualdad de la época virreinal, en particular respecto de los "indios", y se mostraba satisfecho de que a finales del siglo XIX "los obreros son ciudadanos que se sientan en los comicios y tribunales de la patria", ${ }^{87}$ como afirmó en la arenga de 1902. Y sin embargo, algunas desigualdades seguían presentes en sus discursos.

Tal vez lo más claro es la desigualdad entre los géneros femenino y masculino. Es importante señalarlo, Rivera era defensor de la educación de las mujeres. En su discurso de 1892 incluso rechazó como un engaño que se les denominara el "sexo débil”, y argumentó a favor de su educación para asumir sus "deberes para con los demás como hijas, como esposas, como madres y como ciudadanas" ${ }^{88}$ Pero ello no evitó que unos años después, hablara de su hermana religiosa que, "venciendo la debilidad de su sexo" logró llegar a San Cristóbal de Las Casas, que rechazara las lágrimas que calificaba de "llantos mujeriles" en honor de Pedro Moreno, o que caracterizara a Manuela Herrera, insurgente y patriota, y por ello "vergüenza de algunos hombres". ${ }^{89}$ Esto es, la fuerza y el valor no dejaban de estar del lado masculino fundamentalmente. Sobre todo, lo más paradójico, que hasta donde sabemos ese uso del término "ciudadana" nunca implicó hablar de la posibilidad de que efectivamente las mujeres tuvieran derechos políticos activos. Hacia el futuro, no parece haber previsto como parte del progreso del que tanto habló que hombres y mujeres tuvieran igualdad de derechos.

\footnotetext{
${ }^{86}$ Rivera, Sermón que predicó el Dr. D. Agustín Rivera en la Primera Comunión Eucarística, p. 6.

87 Rivera, Arenga de Agustín Rivera el día de la Fiesta, p. 10.

${ }_{88}$ Rivera, Discurso pronunciado por Agustín Rivera en la función de distribución de premios, p. 8.

${ }^{89}$ Respectivamente: Rivera, Despedida del siglo XIX, p. 3. Rivera, “Arenga con que el Sr. Dr. D. Agustín Rivera contestó”, p. 2. Rivera, Arenga de Agustín Rivera el día de la Fiesta, p. 1.
} 
En conjunto, tratándose de la mujer, y considerando que el personaje femenino al que más aludió fue sin duda la Virgen María, era más común escucharlo hablar de lo que hoy nosotros llamamos la sexualidad, casi sobra decir que conforme a los principios del cristianismo, idealizando por tanto la castidad y pureza femeninas. ${ }^{90} \mathrm{Si}$ es cierto que en 1892 pidió a las jóvenes laguenses que estudiaran historia y filosofía, antes, en 1876 se había afirmado en otra educación más fundamental para ellas: en la Virgen de Guadalupe, "y no en esa multitud de sistemas descabellados de educación [...] aprenderán las doncellas la modestia y la castidad", decía entonces. ${ }^{91}$ Parece haber habido pocos cambios al respecto a lo largo de su trayectoria. Casi sobra decir que las relaciones sexuales legítimas no eran concebidas por nuestro autor sino como "amor conyugal". ${ }^{92}$ Es mucho menos frecuente, pero también existen expresiones de rechazo implícito a los "lances de damas" y, en particular a través de la crítica al Don Juan Tenorio de Zorrilla, a la sexualidad masculina desbordada. ${ }^{33}$ Fue a las mujeres a las que se dirigió en particular en la materia. Así, en 1904 no dudaba en decirle a la niña Genoveva Anaya, en su primera comunión, "que lo pierdas todo, como no seas una mujer perversa". ${ }^{4}$

En fin, no era tema primordial pero aparece también, al final del Discurso sobre el teatro, una advertencia contra el "afeminamiento", producto de separar "los placeres de la imaginación" y del trabajo. ${ }^{95}$ La cuestión de la frontera de los géneros a través de la indumentaria le parecía obvia hasta el punto que en una nota

90 Sobre todo Rivera, Sermón de la Natividad de María; Rivera, Sermón de Nuestra Señora de Guadalupe y Rivera, Sermón de la Purificación de María. ${ }_{91}$ Rivera, Sermón de Nuestra Señora de Guadalupe, p. 5.

92 Rivera, Sermón que predicó el Dr. D. Agustín Rivera en la Primera Comunión Eucarística, p. 7.

${ }_{93}$ Rivera, Discurso pronunciado por Agustín Rivera en la fiesta en honor, p. 2. Rivera, La poesía estudiada a los 91 años, pp. 80-81.

${ }^{94}$ Rivera, Sermón de los dolores i gozos de Sr. San José, p. 11.

95 Rivera, Discurso sobre el teatro, p. 14. 
de la versión impresa de ese mismo texto criticaba con ironía el travestismo del teatro del siglo xviI, no menos que la superstición de los reyes que, prohibiendo la presencia de mujeres en los escenarios, obligaban a que aparecieran "galanes haciendo el amor a damas de velludos brazos y manos grandes y nervudas". ${ }^{96}$ No sobra tampoco decir que las relaciones homosexuales eran directamente impronunciables para Rivera: de la Égloga II de Virgilio apenas llegó a decir en el Discurso sobre la Poesía que no se sabía si su argumento era "inocente" o "nefando". 97

En segundo lugar, una ambigüedad muy particular del autor es la de las clasificaciones sociales. Aunque al final el exordio de su primer sermón sobre la Eucaristía en 1907 pedía "el lenguaje claro que entiendan hasta los artesanos, y al mismo tiempo sublime", ${ }^{98}$ es difícil discernir con claridad su aprecio por las clases sociales populares. Tal vez la mayor expresión de Rivera a su favor haya sido en el discurso de 1892, en el que decía con claridad "estoy muy lejos de despreciar el afecto y los votos de los plebeyos". Más todavía, en una nota al pie incluida en la versión impresa justo en ese pasaje se dedicaba a revelar que las monarquías de Antiguo Régimen en realidad se engañaban al menospreciar a las clases populares; en ellas, "en el orden de los derechos todos los hombres desaparecen ante uno solo; más en el orden de los hechos ¿qué vale el monarca sin el jornalero?”. ${ }^{99}$ $\mathrm{Y}$ sin embargo, de cuando en cuando sus discursos presentan expresiones que para nosotros podrían resultar elitistas. En el Discurso sobre los Hombres Ilustres de Lagos, por ejemplo, al mencionar a Juan Pablo Anaya, no dejó pasar que era "de familia acomodada, como casi todos los personajes cuya alabanza tiene

\footnotetext{
${ }_{96}$ Rivera, Discurso sobre el teatro, p. 28.

97 Rivera, La poesía estudiada a los 91 años, p. 13.

98 Rivera, Sermón sobre la Eucaristía, p. 4.

99 Rivera, Discurso pronunciado por Agustín Rivera en la función de distribución, pp. 3-4.
} 
por objeto este discurso". ${ }^{100}$ De hecho, en ese discurso y en el de 1906, la familia y el linaje no dejaban de tener su peso particular en los juicios que expresaba desde las tribunas. En el segundo, al detenerse a mencionar a cada uno de esos héroes de la independencia laguenses, señalándolos por sus familias y saludando a sus descendientes, prácticamente parecía estar erigiendo una nueva nobleza republicana. ${ }^{101}$

Aunque llegó a hablar de "progreso radical" y de revoluciones, nuestro autor estaba muy lejos de favorecer corrientes más radicales de reorganización de la sociedad. En la plática de 1893 señalaba que el "bienestar social” era producto de la libertad y de la ilustración, pero también de la propiedad. No es raro entonces que, de manera puntual pero precisa, encontremos en sus discursos expresiones breves de rechazo al anarquismo y concretamente contra Pierre-Joseph Proudhon. ${ }^{102}$ Empero, no es que fuera ajeno completamente a los problemas sociales de su tiempo. Tal era, en parte, uno de los motivos de su aprecio por el poema Los parias de Salvador Díaz Mirón; era un texto "docto", decía en su último discurso, porque mostraba "una verdad social de grandísima importancia”, ${ }^{103}$ pero ésta no generaba en el ya nonagenario escritor público una reacción particular. De las tres claves del bienestar social, se diría que promovía el aumento de la libertad y de la ilustración, pero estaba completamente fuera de su horizonte de perspectivas la necesidad de una más justa distribución de la propiedad.

Hay pasajes de ese último discurso en que es posible identificar afirmaciones deterministas en lo social. El "carácter" o "genio" natural parecía que podía volverse infranqueable, de forma que: "unos nacen para abogados, otros para médicos, otros para

100 Rivera, Discurso sobre los Hombres Ilustres de Lagos, p. 11.

101 Rivera, Discurso que pronunció Agustín Rivera en la Fiesta del 27 de octubre de 1906, pp. 1-2.

102 Rivera, Discurso sobre el teatro, p. 13.

103 Rivera, La poesía estudiada a los 91 años, p. 28. 
militares, otros para poetas, otros para artesanos, otros [...] para cuidar gansos y guajolotes, animales simples que exigen muy poca capacidad intelectual para su cuidado; otros para otra clase de acciones, y otros son de aquellos que Lombroso llama criminales natos" ${ }^{104}$ Esta fue la única vez que, al menos en sus piezas oratorias, Rivera llegó a mencionar al célebre criminólogo italiano, pero ya en 1900 había enlistado entre los avances del siglo XIX a las penitenciarías, ${ }^{105}$ por lo que no resulta del todo inesperado. Sin embargo, no deja de contrastar con su aprecio por las posibilidades que la educación y la religión podían ofrecer al hombre para mejorar su carácter natural. Esos criminales natos acaso constituirían un límite a lo que había dicho en cambio en su sermón de 1901: "ninguno tomaría un puñal, y cometería ningún otro pecado mortal, si antes, con la gracia de Dios, meditara en las consecuencias del pecado mortal en esta vida y en la otra”. ${ }^{106}$

Rivera ya no puede contestarnos esas preguntas, pero son buena prueba de la complejidad de su obra, que dejó no sólo proyectos coherentes sino también discontinuidades. En todo caso, en el mismo discurso que se leyó en Comitán en su nombre, se nota también que no había estrictamente una utopía secular para nuestro autor. A pesar del progreso que esperaba para el siglo $\mathrm{xx}$, la historia universal no podía dejar de ser un constante contraste entre el bien y el mal: "hasta el fin del mundo ha de haber bienes y males, usos y abusos, cerebros y corazones bien organizados, y cerebros y corazones mal organizados”. ${ }^{107}$ Acaso, pero no podemos confirmarlo, uno de esos males y abusos habría sido la desigualdad socioeconómica.

En cambio, la desigualdad que sí parecía tener remedio en el futuro y que Rivera esperaba era la de los “indios”. Nuestro

104 Rivera, La poesía estudiada a los 91 años, p. 19.

105 Rivera, Despedida del siglo XIX, p. 5.

106 Rivera, Sermón de la Purificación de Maria, p. 5.

107 Rivera, Despedida del siglo XIX, p. 5. 
autor los mencionó en nueve de sus piezas oratorias. En principio no podía dejar de referirse a ellos como los pueblos que recibieron la evangelización. Aquí cabe decir que fue también autor de un Compendio de la Historia Antigua de México (1876), del que sólo publicó el primer tomo y que ameritó una censura canónica por varios argumentos que causaron controversia, tal vez el más importante: trató de "salvar” (literalmente, en términos teológicos) a los aztecas por ser sólo “fanáticos” y no directamente "salvajes" con sus rituales, en particular los sacrificios humanos. ${ }^{108}$ Entonces se le acusó en la mitra de Guadalajara de "excesivo afecto" hacia esos pueblos; sin embargo, en sus sermones y discursos no deja de haber una sustancial diferencia entre esas civilizaciones y la civilización occidental cristiana. De hecho, en más de una ocasión aparecen directamente como pueblos "bárbaros”, pero aun así seres racionales susceptibles de salvarse gracias a la evangelización. ${ }^{109}$

Mas durante la época virreinal, de manera muy contundente decía Rivera en su discurso del Centenario de la Independencia, "los indios estaban embrutecidos, enervados y convertidos en animales de carga". ${ }^{110}$ Para nuestro autor esa condición se había conservado tras la independencia en virtud de la ignorancia en que habían sido mantenidos, y era evidente en sus prácticas religiosas. No tenía exactamente palabras de aprecio para sus fiestas, en particular las de Santiago Apóstol, antes bien aseguraba en 1902 que, cuando “se ilustren”, "se arrepentirán de haber dado su dinero y haber sido tan tontos durante siglos". ${ }^{111}$ Prácticamente su única aportación a la historia habría sido como parte de los ejércitos insurgentes, desde luego bajo liderazgos no

108 Rivera, Compendio de la Historia. Rivera, Tres documentos.

109 En particular en Rivera, Sermón de la Santísima Virgen de Guadalupe.

110 Rivera, Discurso pronunciado por Agustín Rivera en el Palacio Nacional, p. 11.

111 Rivera, Arenga de Agustín Rivera el día de la Fiesta, p. 8. 
indios, como el de Hidalgo. ${ }^{112}$ Aquí tampoco tenemos una reflexión completa de Rivera, por lo que no sabemos exactamente qué futuro esperaba para esos pueblos, pero acaso no hubiera visto mal su cabal integración al orden occidental.

No lo decía de manera necesariamente explícita en sus discursos y sermones, pero la civilización cristiana y el progreso que auguraba el sabio de Lagos, aunque fundados en la libertad y la igualdad, como podemos ver, no dejaban de favorecer a unos sectores de la sociedad más que a otros.

\section{COMENTARIOS FINALES}

Leer los sermones y discursos de Rivera es, sin duda, una lección de lo inactual, en más de un sentido. Primero, porque muestra que un intelectual liberal podía ser, no sólo sacerdote, sino subir a tribunas laicas a predicar sobre héroes de una nación cuyo fundamento era asimismo laico, pero hablando de su pertenencia a una civilización que no podía ser sino cristiana. Su oratoria era más católica de lo que algunos escritores ultramontanos hubieran querido aceptar. Respetaba la distinción entre lo propio de la "catedra del Espíritu Santo" y la tribuna cívica, pero sobre todo a favor de la primera. A sus sermones no llevaba cuestiones profanas, sino que exponía los fundamentos trascendentes de sus planteamientos. En cambio, en sus discursos podía no sólo criticar las prácticas religiosas tradicionales (que probablemente era lo que más resaltaba), sino también difundir mensajes morales y religiosos. Predicaba desde el púlpito, pero también desde la tribuna, y en cambio no criticaba tanto desde el primero cuanto desde esta última. En uno y otra no dejaba de fundarse en un discurso teológico: detrás

112 Por ello decía, "todas las revoluciones sociales se han hecho por el pueblo bajo, dirigido por hombres superiores”. Rivera, Discurso pronunciado por Agustin Rivera en el Palacio Nacional, pp. 9-10. 
de la historia de los pueblos, patrias y naciones, del progreso y de la civilización, estaba la voluntad de Dios, que había establecido una naturaleza humana capaz de asociarse y progresar, aunque imperfecta y necesitada de corrección por medio de la educación y de las artes, incluida la propia oratoria. Si bien esto permitía una cierta autonomía para la esfera política y científica, que podían aprovechar que esa voluntad divina sólo intervenía indirectamente en ellas, acotaba de forma estricta la de la esfera artística, esta sí al servicio de la moral.

En segundo lugar, es inactual por su horizonte de expectativas optimista. Rivera es testimonio de un momento en que las élites del mundo occidental confiaban en que el futuro sería siempre mejor. Nos resulta ajeno en parte porque ya no están vigentes como valores preponderantes (aunque no dejan de estar demasiado extendidos en nuestras sociedades) los de unas élites que tendían al machismo, al elitismo y al racismo. Así pues, estos sermones y discursos son también importantes para cuestionar esos otros temas culturales de tiempos del porfiriato, siempre presentes pero de formas sutiles, como la sexualidad y la exclusión.

En ese sentido, las piezas oratorias de Agustín Rivera nos ayudan a ver de nuevas formas la cultura del siglo xIx, pero también nos recuerdan hasta qué punto han existido otras posibilidades de articular conceptos que por sí mismos no nos resultan tan ajenos, como tradición y modernidad, religión y política, arte y moral, etc. Tal vez lo que cabe apreciar de su labor de orador es ese esfuerzo de ofrecer a su público respuestas originales a las inquietudes de su tiempo, desde una incansable erudición y una inagotable imaginación.

\section{SIGLAS Y REFERENCIAS}

HNDM Hemeroteca Nacional Digital de México (http://www.hndm. unam.mx/) 
Aguirre Salvador, Rodolfo, El mérito y la estrategia. Clérigos, juristas y médicos en Nueva España, México, Universidad Nacional Autónoma de México, Plaza y Valdés, 2003.

Agulhon, Maurice, Historia vagabunda. Etnología y política en la Francia contemporánea, México, Instituto de Investigaciones Dr. José María Luis Mora, 1994.

BRADING, David, "La devoción católica y la heterodoxia en el México borbónico”, en Ramos Medina y García Ayluardo (coords.), 1997, pp. 25-49.

Brading, David, Mexican Phoenix. Our Lady of Guadalupe: Image and tradition across five centuries, Cambridge, Cambridge University Press, 2001.

BRISEÑo Senosiain, Lilián, "La moral en acción. Teoría y práctica durante el Porfiriato", en Historia Mexicana, Lv: 2 (218) (oct.-dic. 2005), pp. 419-460.

Camacho Mercado, Eduardo, Frente al hambre y al obús: Iglesia y feligresía en Totatiche y el cañón de Bolaños, 1876-1926, Guadalajara, Arquidiócesis de Guadalajara, Universidad de Guadalajara-Lagos, 2014.

Camacho Mercado, Eduardo, "Beneficios eclesiásticos y actividades profanas. Opciones, estrategias y elecciones de vida de los sacerdotes Sanromán en el siglo XIX”, en CRUZ LiRA (coord.), 2016, pp. 15-41.

Carbajal López, David, "Entre concordancias, debates y paralelos: Francia en el discurso conciliador del doctor Agustín Rivera y Sanromán, 18761897”, en Historia Mexicana, LXvII: 1 (265) (jul.-sep. 2017), pp. 295-340.

Chinchilla Pawling, Perla, "La república de las letras y la prédica jesuita novohispana del xviI. Los paratextos y la emergencia del arte como sistema", en Estudios de Historia Novohispana, 41 (2009), pp. 79-104.

Chinchilla Pawling, Perla, El sermón de misión y su tipología. Antología de sermones en español, nábuatl e italiano, México, Universidad Iberoamericana, 2013.

Connaughton, Brian, "Agustín Rivera, Feijoo y la epopeya nacional mexicana”, en Olivera y Meza (coords.), 2009, pp. 13-39.

Connaughton, Brian, "Agustín Rivera: ¿autor liberal de planteamientos modernos?”, en Cruz LiRa (coord.), 2016, pp. 243-263. 
Cortés Manresa, Enriqueta Lorena, "Liberalismo y civilización. Comentarios a un Juicio crítico, de Agustín Rivera", en Cruz Lira (coord.), 2016, pp. 139-167.

Cruz Lira, Lina Mercedes, Vecinos de casa poblada, Lagos de Moreno, Jal., México, culagos Udg, 2017.

Cruz Lira, Lina Mercedes (coord.), Agustín Rivera: Vida, obra y contextos, Lagos de Moreno, Universidad de Guadalajara-Lagos Ediciones, 2016.

Di Stefano, Roberto, El púlpito y la plaza. Clero, sociedad y política de la monarquía católica a la república rosista, Buenos Aires, Siglo Veintiuno Editores, 2004.

Egido, Teófanes, Los sermones gerundianos, Alicante, Biblioteca Virtual Cervantes, 2010, disponible en línea en http://www.cervantesvirtual.com/nd/ ark:/59851/bmcns199.

Hernández Luna, Juan, Dos ideas sobre la filosofía en la Nueva España, México, Universidad Nacional Autónoma de México, 1959.

LEMPÉRIÈre, Annick, "Los dos centenarios de la independencia mexicana (1910-1921): de la historia patria a la antropología cultural”, en Historia Mexicana, XLv: 2 (178) (oct.-dic. 1995), pp. 317-352.

Mijangos, Pablo, The Lawyer of the Church. Bishop Clemente de Jesus Munguia and the Clerical Response to the Mexican Liberal Reforma, Lincoln y Londres, University of Nebraska Press, 2015.

Morán, Manuel y José Andrés Gallegos, “El predicador”, en Vilari (ed.), 1992, pp. 165-199.

Munguía, Clemente, Estudios oratorios u observaciones críticas sobre algunos discursos de los oradores más clásicos antiguos y modernos, precedidas de un discurso sobre la elocuencia y de algunas arengas sobre varios géneros de literatura, Morelia, Imprenta de Ignacio Arango, 1841.

Muñoz Moreno, Rafael, Rasgos biográficos del Sr. Dr. D. Agustín Rivera y Sanromán, Lagos de Moreno, Imprenta López Arce, 1906.

Olivera, Luis y Rocío Meza (coords.), Archivo Agustín Rivera y Sanromán de la Biblioteca Nacional, 1547-1916, México, Universidad Nacional Autónoma de México, El Colegio de Jalisco, 2009, t. III. 
Pani, Erika y Alicia Salmerón (coords.), Conceptualizar lo que se ve. François-Xavier Guerra historiador. Homenaje, México, Instituto de Investigaciones Dr. José María Luis Mora, 2004.

Pérez Rayón, Nora, “La modernidad y sus mitos: Juárez, el benemérito”, en Pani y Salmerón (coords.), 2004, pp. 215-249.

Ramos Medina, Manuel y Clara García Ayluardo (coords.), Manifestaciones religiosas en el mundo colonial americano, México, Instituto Nacional de Antropología e Historia, Universidad Iberoamericana, Centro de Estudios de Historia de México Condumex, 1997.

Rivera, Agustín, Sermón de la Natividad de María predicado por el Dr. Agustín Rivera en la capilla de Nuestra Señora de Loreto el día 8 de septiembre de 1854..., San Juan de los Lagos, Tipografía de José Martín, 1874.

Rivera, Agustín, Sermón de la Santísima Virgen de Guadalupe predicado por Agustín Rivera en el Sagrario de Guadalajara el día 12 de diciembre 1859, San Juan de los Lagos, Imprenta de José Martín, 1875.

Rivera, Agustín, Concordancia de la razón y la fe, San Juan de los Lagos, Tipografía de José Martín, 1876.

Rivera, Agustín, Compendio de la Historia Antigua de México, San Juan de los Lagos, Tipografía de José Martín, 1876.

Rivera, Agustín, Tres documentos sobre el tomo $1^{\circ}$ del Compendio de la Historia Antigua de México escrito por Agustín Rivera..., Lagos de Moreno, Tipografía de Vicente Veloz, 1881.

Rivera, Agustín, Los dos estudiosos a lo rancio, o sea Diálogo crítico escrito en Lagos en 1881, Lagos de Moreno, Tipografía de Vicente Veloz, 1882.

Rivera, Agustín, Sermón de Nuestra Señora de Guadalupe predicado por el Dr. D. Agustín Rivera..., San Juan de los Lagos, Tipografía de José Martín y Hermosillo, 1882.

Rivera, Agustín, Principios críticos sobre el vireinato [sic] de la Nueva España i la Revolución de Independencia, Lagos de Moreno, Tipografía de Vicente Veloz, 1888, t. 2.

Rivera, Agustín, Juicio crítico de los sermones de fray Juan de San Miguel..., Lagos de Moreno, Tipografía de Vicente Veloz, 1890. 
Rivera, Agustín, Tres artículos sobre el elogio que en su arenga del 27 de octubre próximo pasado bizo de los Principios proclamados por la Revolución Francesa en 1789, Lagos de Moreno, Ausencio López Arce impresor, 1891.

Rivera, Agustín, El cempasúchil, Lagos de Moreno, Ausencio López Arce impresor, 1891.

Rivera, Agustín, La vocación de Simón Bar Jona, Lagos de Moreno, Ausencio López Arce impresor, 1892.

Rivera, Agustín, La pobre bumanidad a través de la púrpura, el cetro, el libro, el laurel y el crucifijo..., Lagos, Ausencio López Arce impresor, 1893.

Rivera, Agustín, Discurso pronunciado por Agustín Rivera en la función de distribución de premios a los alumnos de los Liceos del Padre Guerra..., Lagos de Moreno, Ausencio López Arce impresor, 1894.

Rivera, Agustín, Plática de Agustín Rivera en la primera comunión eucarística del niño..., Lagos de Moreno, Ausencio López Arce impresor, 1894.

Rivera, Agustín, Discurso sobre los Hombres Ilustres de Lagos..., Lagos de Moreno, Ausencio López Arce e Hijo Tipógrafos, 1895.

Rivera, Agustín, Sermón que predicó el Dr. D. Agustín Rivera en la Primera Comunión Eucarística de los Niños..., Lagos de Moreno, Imprenta de Ausencio López Arce e Hijo, 1899.

Rivera, Agustín, Sermón de la Purificación de María predicado por el Sr. Dr. D. Agustín Rivera..., Lagos de Moreno, Imprenta de López Arce, 1901.

Rivera, Agustín, “Arenga con que el Sr. Dr. D. Agustín Rivera contestó al recibir el Diploma”, en Piezas Literarias en la Fiesta de Moreno en Lagos, el 30 de octubre de 1901, Lagos de Moreno, Imprenta López Arce, 1901, pp. 2-4.

Rivera, Agustín, Despedida del siglo XIX..., Lagos de Moreno, Imprenta López Arce, 1902.

Rivera, Agustín, Arenga de Agustín Rivera el día de la Fiesta en honra del Héroe de la Patria Pedro Moreno..., Lagos de Moreno, Imprenta López Arce, 1903. 
Rivera, Agustín, Discurso pronunciado por Agustín Rivera en la fiesta en honor del héroe de la patria Pedro Moreno..., Lagos de Moreno, Imprenta López Arce, 1903.

Rivera, Agustín, Sermón de los dolores i gozos de Sr. San José, que predicó Agustín Rivera en la primera comunión eucarística que hizo la niña..., Lagos de Moreno, Imprenta López Arce, 1904.

Rivera, Agustín, Discurso que pronunció Agustín Rivera en la fiesta de la colocación de la primera piedra del monumento a la memoria del héroe de la patria Pedro Moreno en Lagos de Moreno, el día 15 de mayo de 1904, Lagos de Moreno, Imprenta López Arce, 1904.

Rivera, Agustín, Discurso que pronunció Agustín Rivera en la Fiesta del 27 de octubre de 1906 en Lagos de Moreno, Lagos de Moreno, Imprenta López Arce, 1906.

Rivera, Agustín, Sermón sobre la Eucaristía predicado por Agustín Rivera en la primera comunión del niño..., Lagos de Moreno, Imprenta de López Arce, 1907.

Rivera, Agustín, Discurso sobre el teatro pronunciado por Agustín Rivera en el Teatro Rosas Moreno en la fiesta de la conclusión del mismo teatro el día 6 de agosto de 1907, Lagos de Moreno, Imprenta López Arce, 1907.

Rivera, Agustín, Recuerdos de mi capellanía de las capuchinas de Lagos, Lagos de Moreno, s.p.i., 1908.

Rivera, Agustín, Sermón de la Eucaristía predicado por el Sr. Dr. D. Agustín Rivera en la primera comunión de los niños..., Lagos de Moreno, Imprenta de López Arce, 1909.

Rivera, Agustín, Discurso pronunciado por Agustín Rivera en el Palacio Nacional de la capital de México, en la apoteosis de los Héroes de la Independencia de México..., México, Imprenta de Manuel León Sánchez, 1910.

Rivera, Agustín, La poesía estudiada a los 91 años nueve meses o sea Discurso sobre la Poesía..., Morelia, Tipografía del Gobierno en la Escuela de Artes, 1916.

TAYLOR, William B., Ministros de lo sagrado. Sacerdotes y feligreses en el México de la segunda mitad del siglo XVIII, Zamora, El Colegio de Michoacán, Secretaría de Gobernación, El Colegio de México, 1999. 
Torre Villar, Ernesto de la, "Polémica de Agustines", en Historia Mexicana, III: 1 (9) (jul.-sep. 1953), pp. 129-133.

Traslosheros, Jorge Eugenio, "Señora de la historia, Madre mestiza, Reina de México. La coronación de la Virgen de Guadalupe y su actualización como mito fundacional de la patria, 1895”, en Signos Históricos, 7 (2002), pp. 105147.

VILARI, Rosario (ed.), El hombre barroco, Madrid, Alianza Editorial, 1992. 